\title{
Exploring the role of content knowledge in responsive teaching
}

\author{
Lisa M. Goodhew and Amy D. Robertson \\ Seattle Pacific University Department of Physics, Seattle, Washington 98119-1997, USA
}

(Received 11 August 2015; published 27 January 2017)

\begin{abstract}
In this paper, we begin to explore the role of content knowledge in responsive teaching (RT), using in situ data to draw out and speak to a latent disagreement within the literature. We claim that one role that content knowledge plays in RT is to support teachers in eliciting, seeing, and then pursuing disciplinary connections within their students' thinking. We suggest an approach to teacher education that draws on the historical wisdom of the physics education research community, in which teachers develop content knowledge and then practice using that knowledge to listen and respond to student thinking.
\end{abstract}

DOI: 10.1103/PhysRevPhysEducRes.13.010106

\section{INTRODUCTION}

Recent STEM education reforms [1,2] emphasize student engagement in scientific practices, alongside and integrated with their learning of core content. Concurrent (and consistent) with this emphasis are reimaginings of the core practices of ambitious, equitable STEM teaching [2], including the centrality of attending and responding to students' thinking. Together, these visions call for science classroom practice that is centered on the pursuit and refinement of students' intuitive sense making about the physical world. Responsive teaching (RT) —or teaching that (i) foregrounds the substance of students' ideas, (ii) recognizes disciplinary connections within students' ideas, and (iii) takes up and pursues the substance of students' ideas $[3,4]$ - is one instructional approach that exemplifies these visions, and it embeds the assumption that students come to the classroom with "wonderful ideas" [5] that can serve as the foundation for the class' learning. In responsive classrooms, the curriculum emerges (at least in part) from these ideas and from students' generative engagement and questions.

As we will describe in the following, there is a latent disagreement in the literature about the role of content knowledge in responsive teaching. This paper will use classroom episodes to explore the question, "What role(s) does content knowledge play in responsive teaching?", with implications for physics teacher professional development. First, we introduce RT, review what the literature has said about its importance, and synthesize across discussions of what teachers need to know in order to enact it.

Published by the American Physical Society under the terms of the Creative Commons Attribution 3.0 License. Further distribution of this work must maintain attribution to the author(s) and the published article's title, journal citation, and DOI.

\section{A. What is responsive teaching?}

Responsive teaching, as construed here and elsewhere, is an instructional approach that stems from several foundational assumptions: that students come to classrooms with a wealth of productive knowledge and experience; that this wealth is too rich and diverse for teachers and curricula to know it in advance; and that sense making is a natural part of how people interact with the world, such that the ideas students are bringing to bear are sensible in some way [6-9]. From these assumptions comes the stance that teaching begins with listening and seeking to understand.

For these reasons, responsive instruction foregrounds the substance of students' ideas [4,5,10-30]; teachers attend to the meaning that students are making of their disciplinary experiences, assuming a stance of seeking to understand rather than evaluating. Responsive instruction also seeks out disciplinary connections within students' ideas $[4,18,21,23,24,26,27,29-35]$, assuming that there is inherent sensibility and "disciplinary progenitors" [36] within student ideas. These disciplinary progenitors-or "seeds of science" [30] — may be, for example, the beginnings of canonical understanding, the instantiation of specific scientific practices, or affective experiences that promote feelings of pleasure in doing science. In RT, the teacher "consider[s] the [discipline] in relation to the [students] and the [students] in relation to the [discipline]" [27]. RT also adapts or builds instruction on the basis of students' ideas $[4,14-16,18,21,23,24,26,27,29,33,37-43]$, in ways that both preserve the essence of student thinking and make progress along disciplinary dimensions. In this sense, responsive instruction is emergent (at least in part), on short- and longer-term scales. Hammer, Goldberg, and Fargason [4] write

“A responsive approach... is to adapt and discover instructional objectives responsively to student thinking. The first part of a lesson elicits students' generative engagement around some provocative task or situation (or, perhaps, by discovering its spontaneous emergence). 
From there, the teacher's role is to support that engagement and attend to it - watch and listen to the students' thinking, form a sense of what they are doing, and in this way identify productive beginnings of scientific thinking. In this way, the teacher may select and pursue a more specific target, in a way that recognizes and builds on what students have begun."

To illustrate what RT looks like, we use the following example from Sharon Fargason's third-grade class at Fay Elementary in San Diego. ${ }^{1}$ Sharon's students have been engaging in an investigation of "how to make a car go without touching it." They have explored how to do this with magnets and electricity, and now they are discussing what they have learned. One student observes that the electricity and magnets are "like magic," and Sharon follows up, asking Sharon: How is it like magic?

Koser: I think because it does something that other things can't do.

Sharon: What do you mean it does something other things can't do?

Koser: Like, um, only balloons could, uh, make your hair stand up and um, uh, um, other things, when you use them, it doesn't make your hair stand up.

Sharon: Do you mean like if I put a magnet up here it wouldn't make my hair stand up?

Koser: No, because um, uh, if you put a magnet on your hair, it will just stay on top of your hair, but if you, even if you rub it, um, it will just stay on your head. But if you take a balloon and rub it, it will uh make your hair stand up.

Sharon: Diego?

Diego: It's not really magic because um...

Vicky: She said it's like magic.

Diego: It's not really magic cause um you know those little shock thingies? That give you a shock? On the play structure? It's like those. Those pick your hair up.

Students: Oh yeah!

Vicky: Oh yeah! When you go down the slide, your hair goes up.

Sharon: It picks it up. (Class erupts into conversation.) Your TV does that. Mmmhmm

In this short snippet, students are noticing "significant features and patterns" [44] among their experiences of static electricity and evaluating one another's ideas by engaging in argument from evidence. For example, Koser notices that a rubbed balloon can pick up your hair, whereas other things cannot, and Diego pushes back on Koser's suggestion that electricity is "like magic," because "pick [ing] your hair up" is not an out-of-the-ordinary experience. Students' engagement in these scientific practices is integrated with and consequential to the refinement of their

\footnotetext{
${ }^{1}$ We are grateful to Sharon for providing transcript for this example.
}

ideas about electricity; they are noticing and arguing and constructing in order to better understand examples of electric phenomena and their limits. Sharon's role as their teacher is to advance their work by pressing them to explain what they mean and sticking with the substance of their ideas. She continues their discussion forward (after this snippet) by reiterating both that there are many different experiences that can make your hair stand up and that there is something special about electricity, saying,

“You're right! It's like there's something about rubbing that makes it come up. And it's not just a balloon. Huh? It's a slide outside. It's your $T V^{2} \ldots$ But it is kind of like magic because instead of stuff usually falling down, like, if you rub a balloon...[student finishes her sentence, saying, "it's like gravity doesn't pull it down]."

She later affirms one student's confusion, saying, "That's a good question!," when the student says, "I'm confused about what she said, like, how could, if gravity pulls you down, how could hair go up?"

A second example, this time from high school physics, is depicted in David Hammer's Discovery Learning and Discovery Teaching [26]. During a unit on electrostatics, one student (Camille) spontaneously notices that if she brings a neutral pie dish near a charged foam plate and then touches the pie dish with her finger, the foam plate lifts off the table. David deviates from the curriculum in response, naming this phenomenon "the Marino phenomenon" after Camille, and then inviting the class to explore and explain it over the next several days. Three students in the course propose what the class names the "HAM Theory" (again, after the three students who author it), positing that positive and negative charges can move within materials, so that different parts of an object might have different charge, and that "different materials have different tendencies to accept or give up electrons." The students use their theory to explain the behavior of the foam plate in the Marino phenomenon: when the pie dish is brought near the negatively charged foam plate, "negative charge is repelled toward the top of the [pie dish], and positive charge is attracted to the bottom." Negative charges leave the dish via the finger that touches the top, and the dish is left with a net positive charge, which then attracts the negatively charged foam plate. Several students object to this explanation, arguing that "the [pie dish] could [not] be charged one way on top and another way on the bottom." To try to confirm or disconfirm different models of what is happening, David and his students devise and conduct various experiments. Students begin to identify inconsistencies between particular models and the observed behavior of the objects, and they propose additional experiments to explore the extent to

\footnotetext{
${ }^{2}$ For clarity, in this episode, Sharon and her students are referring to a cathode-ray-tube TV (rather than a plasma or LCD TV).
} 
which the remaining models "hold up." The quiz that Hammer gives students after these preliminary explorations asks them to defend their position in the debate, to address counterarguments, and to design an experiment that would distinguish between the two remaining models.

Throughout this example, David invites students to bring their own models to bear on investigations of charged phenomena, and he seeks to understand how the authors of each model would make sense of new phenomena they observed. He notes the "seeds" of disciplinary ideas and practices he sees therein. For example, in Camille's discovery of the Marino phenomenon, David sees opportunities for students to participate in science as a socially constructed endeavor ("it was another opportunity to show the students that their discoveries mattered"), to see observation and exploration as central to scientific progress, and to build connections to physicists' notions of induced polarization and charging by induction. Over the course of these several days, he deviates from the intended order of the worksheets his students are completing to pursue explanations for the Marino phenomenon. As he does so, David promotes classroom practice that mirrors that of science, instantiating the authentic integration of content and practices called for in the NGSS: students are encouraged to explore their observations, to explain what they see in terms of models, to consider competing models and counterarguments, and to reconcile inconsistencies between their models and their observations.

\section{B. Why is responsive teaching important?}

In these snippets and others like them, we can see some of the reasons that researchers and teachers care about RT. Central among them is the sense that RT supports students in building knowledge in ways that are consistent with the practices of science $[4,24,27,28,34,45]$. Experiments, argumentation, model building, and other practices are inspired by and in the service of pressing into students' own ideas, as in the episodes from Sharon's and David's classes above. By distributing authority for the construction and assessment of ideas and by elevating nascent scientific and mathematical practices that emerge in the flow of classroom activity, RT brings students closer to the heart of what it means to do science or mathematics.

Responsive instruction has also been shown to improve students' conceptual understanding, more so than more traditional approaches [15,37-39,43,46-49]. In fact, Fennema et al. [39] found that gains in students' mathematics achievement co-occurred with shifts in teachers' responsiveness to their students' mathematical thinking.

We and others argue that responsive teaching is also important for reasons of equity and agency. Framing students' intuitive ideas as misconceptions may systematically disadvantage students from diverse cultural, linguistic, and socioeconomic communities: “...children most particularly disadvantaged by approaches based in a dichotomous view [e.g., focusing on the correctness vs incorrectness of student thinking] are those whose everyday ways of knowing and talking are seen as being the furthest from those traditionally valued in school science or even in national standards [50]."

On the other hand, framing student ideas as productive beginnings of disciplinary thinking has the potential to broaden participation among historically underserved groups [23,50-56]. Shifting the emphasis away from teacher as knowledge provider-and toward students as agents of their own learning and knowledge constructioncan dismantle systems of privilege within STEM classrooms $[57,58]$.

\section{What do teachers need to know to enact responsive teaching?}

Given these benefits of RT, a number of professional development efforts across the STEM disciplines have been designed to support teachers in learning to enact RT practices $[4,11,18-20,29,30,37-40,42,59-77]$. Within the literature depicting this professional development, there are different takes on the skills, dispositions, and/or knowledge that teachers need to be able to attend and respond to their students' thinking. For example, several say that teachers need to practice engaging and responding to students [66-68,78]:

"Skillful teaching requires appropriately using and integrating specific moves and activities in particular cases and contexts, based on knowledge and understanding of one's pupils and on the application of professional judgment. This integration also depends on opportunities to practice and to measure one's performance against exemplars...Professional training should be designed to help teachers learn to enact these tasks skillfully. Such training would involve seeing examples of each task, learning to dissect and analyze the work, watching demonstrations, and then practicing under close supervision and with detailed coaching aimed at fostering improvement [66]."

Others say that teachers need skill in noticing and pursuing the substance of students' ideas [17$21,29,31,59,65,79]$, developed by intentional practice, often in the context of video clubs:

"Learning to notice in particular ways is part of the development of expertise in a profession [21]."

"...the basis for this research is the claim that the ability to notice classroom interactions is a key feature of teaching expertise...If one believes the claim that the ability to notice is a key feature of teaching expertise, then the next question to ask is how educators and 
researchers might be able to support the development of this ability...[W]e believe that video can also play a significant role in helping teachers learn to notice [18]."

Still others discuss the importance of a commitment to listening to and working to understand the substance of student ideas $[13,28,80]$ :

"Rather than having a predetermined agenda for a sequence of activities or a specific set of content learning goals that need to be met, the learning goals in a responsive curriculum can emerge in the context of student discussions. This approach puts new kinds of demands on both the teacher and the students. The teacher needs to listen carefully to the substance of students' ideas, assess the merits of those ideas, and make next-move decisions accordingly [4]."

"Yet, in a responsive classroom, the teacher's role is to listen to and identify ways to build upon students' thinking, cultivate it, to advance students' scientific knowledge. Learning to listen and reflect upon the substance of students' ideas without focusing on what we want them to be saying can be quite challenging for an instructor... In an effort to address this challenge, several professional development projects in mathematics have focused on helping teachers learn to invite, support and attend to learners' ideas [59]."

And still others argue that it is important for a teacher to frame activities as making sense of observations and experiences, rather than about finding a right answer $[34,81,82]$ :

“...we argue for greater attention to guiding students toward productive framing. Here, we have presented an example from a course designed for future elementary school teachers, a group for whom the need is especially significant. Because we want them to view teaching science as helping students make sense of phenomena, they should experience learning science in that way themselves [34]."

Within the RT literature, there is very little mention of the need for or role of teacher content knowledge, and even among the subtle nods toward the importance of this kind of knowledge, there is some disagreement. For example, Wallach and Even [25] suggest that one teacher's content knowledge may contribute to her overfiltering her students' mathematical thinking. In particular, the authors interview the teacher after she watches two of her students solving a mathematics problem, and they notice that she attends to all of the students' suggested solutions except for one. They suggest that the teacher's "own understanding of the solution as an even number smaller than 15, which does not correspond to [the student's] suggestion, seems to hamper her hearing." Likewise, Russ et al.
[33] express concerns about the overwhelming priority that is sometimes placed on content knowledge and/or canonical understandings - "if we allow our desire for textbook correctness to dictate our assessments in every moment, we risk undermining our overarching goal of developing meaningful understanding of science and scientific knowledge by suppressing the reasoning that leads to it"- - suggesting a mechanism by which content knowledge may constrain a teacher's responsiveness.

On the other hand, quotes from practitioner accounts of RT suggest the importance of content knowledge for understanding the disciplinary significance of students' ideas. For example,

"To do this [RT] productively, I must understand the specific mathematical content and its uses, bases, and history, as well as be actively ready to learn more about it through the eyes and experiences of my students...I must consider the mathematics in relation to the children and the children in relation to the mathematics. My ears and eyes must search the world around us, the discipline of mathematics, and the world of the child with both mathematical and child filters." (Ball, With an Eye on the Mathematical Horizon [27]).

"As an instructor with a long history of teaching about energy, the connections between this representation and the canon were readily apparent as they arose during instruction, even if they were unanticipated in advance." (Atkins and Frank, Examining the Products of Responsive Inquiry [80]).

"These matters presented demands on my understanding and reasoning in physics. There were questions that I needed to solve for myself in these lessons ... more than that, I needed to follow the students' arguments, to understand them on their own terms. Given what they knew and had experienced, were their inferences reasonable and self-consistent, or were they flawed in ways students should be able to recognize? What line of reasoning could I find, starting from the students' positions, that could lead them in the direction of the ideas I hoped they would develop? What might be seeds of expertise in their ideas and reasoning, and what might be impediments? A teacher with inadequate preparation in the discipline would be at a substantial disadvantage in following students' unfamiliar arguments and ideas expressed in unfamiliar vocabulary." (Hammer, Discovery Learning and Discovery Teaching [26]).

In this paper, we begin to explore the research question, "What role(s) does content knowledge play in responsive teaching?" 3 In our analysis, we look within and across

\footnotetext{
${ }^{3}$ To be clear, throughout the paper our use of the term "knowledge" does not assume that this knowledge is either stable or coherent; teacher knowledge could just as easily be (and in many cases likely is) constructed during an interaction.
} 
cases of responsive teaching to understand the content knowledge that teachers are bringing to bear in attending and responding to their students' ideas, including how that content knowledge supports their responsiveness. Our aim is to initiate a data-driven conversation that can speak to the latent disagreement in the literature, and then to inform teacher preparation that answers to current STEM education reforms. In particular, we consider how the collective wisdom of the physics education research communitywhich has largely emphasized the development of teacher content knowledge [83-89] — can play a role in supporting teachers in enacting RT. This conversation is especially important at this juncture in U.S. educational policy, when standards documents $[1,44,90]$ are calling for a new vision of teaching - one that takes up and pursues the substance of student thinking — and at the same time, policymakers are pushing for more accountability to the definition of "'teaching skills' as those skills that enable a teacher, among other competencies, to effectively convey and explain academic content." ${ }^{4}$

We start with a description of our research methodology, and then we introduce readers to the focal episodes from which we selected instances of responsive teaching. We move on to present our analysis, laid out in such a way as to answer our primary research question, "What role(s) does content knowledge play in responsive teaching?" We close with some implications for research and teacher education.

\section{METHODOLOGY}

We have argued for the dynamic nature of responsive teaching - i.e., that in RT, instructors attend to the ideas that emerge from students and adapt their instruction on the basis of these ideas. Here we suggest that questions about what informs such instruction-such as the role of content knowledge in such instruction-are best answered in the context of unfolding interactions between teachers and students. This led us to conduct a series of case studies.

\section{A. Assumptions}

In the tradition of ethnographic case study research, we assume that people construct locally meaningful interpretations of their environments [91-95] and that people take action on the basis of these interpretations (i.e., these interpretations are causal) [91,96]. The meanings that participants make of their experiences (including learning) are dynamic and exist only in the context of local interactions, evolving as participants continually (i) make sense of (and shape) their contexts and (ii) respond to other participants who are simultaneously making sense of (and shaping) the context $[97,98]$. These assumptions bear out in the moment-by-moment dynamics of responsive teaching, in which teachers are actively making meaning of their

\footnotetext{
${ }^{4}$ See www.aacte.org/resources/regulations.
}

students' ideas and actions, responding in ways that attempt to preserve and extend that meaning, and then attending to what happens next to inform their subsequent moves. Further, these assumptions shape our understanding of responsive teaching (and other teaching and learning phenomena) as connected to and shaped by "historical, cultural, institutional, and immediate situational contexts" [99], including teacher knowledge.

\section{B. Episode selection}

To explore the role of content knowledge in responsive teaching, we looked for cases of responsive teaching in the context of lessons about energy, since this content area is the focus of our research team's project-wide efforts [100-104]. Our criteria for calling an episode "responsive" was that it loosely satisfied the three characteristics of responsive teaching we articulate in the Sect. I: teachers were (i) foregrounding the substance of their students' ideas, (ii) recognizing disciplinary connections within their students' ideas, and/or (iii) taking up and pursuing the substance of their students' thinking. We anticipated that some researchers may argue that the role(s) that content knowledge plays in responsive teaching vary by grade level, so we drew from sources that spanned $\mathrm{K}-12$, to get a more general sense of the role of content knowledge in responsive teaching. We used video from the Responsive Teaching in Science project (NSF DRL-0732233), the Energy Project (NSF DRL-0822342), and the What Influences Teachers' Modifications of Curriculum? and Disciplinary Experts in Science Education Research projects (NSF DRL-0455711 and NSF DRL-0733613). We ultimately selected three different episodes-one from an elementary school discussion of the energy in familiar objects (rubber bands, ramps, etc.), one from a middle school discussion of the energy involved in various everyday scenarios (ball rolling down the street, leaves blowing in the street, etc.), and one from a high school discussion of the "Thalia on a Swing" question [105] —each of which highlight a variety of responsive moves that draw on content knowledge to varying extents.

\section{Analytic framework}

After we had selected three episodes, we analyzed them turn by turn [106], breaking them into smaller episodes that corresponded to the teacher's responsive talk moves. For example, we identified lines 12-14 of the Mark transcript (reproduced below) as a single instance of Mark "organizing ideas and revoicing in disciplinary terms":

10. Emily: Like, it has a source of energy.

11. Brianna: Yeah, it has a source of energy, but I mean, and it's, I guess you can say it's involved in energy because you can burn it and it emits flames, but I mean it's like, not, you know, in motion.

12. Mark: So it sounds like you guys are saying, it sounds like you guys are saying a number of things. So first 
off, going back to the bus and the bike, you said that they have kind of a source of energy.

13. (Students agree.)

14. Mark: And so since they have a source of energy, they (were doing) something? Is that?

15. Mark: So the leaves?

16. Brianna: Had a source of energy that moves, had a source to move. But, I mean, like.

17. Mark: Tell me about movement. What does movement have to do with it?

Prior to line 12, Mark was listening to his students' ideas, and after line 14, Mark revoices a different idea.

For each smaller episode, we (i) characterized the responsive move, in some cases using terminology from literature on responsive discourse moves [12,14,15,22,45] and in other cases inventing our own terminology, (ii) identified evidence of content knowledge in use by the teacher (if any), and (iii) examined the ways in which the responsive move relied on the content knowledge we identified. This process was emergent and grounded in the episodes themselves; in selecting our episodes, we did not look for instances that exemplify particular responsive moves, beyond generally satisfying the overarching characteristics of responsive teaching, nor did we seek out particular forms or breadth of content knowledge on display. Instead, we tried to understand the knowledge that a particular teacher was drawing on in making responsive moves and the role(s) that this knowledge played in making the moves. In instances in which we felt we had plausible evidence that a teacher was using content knowledge, we asked ourselves whether any other form of knowledge could account for their actions; these questions led us to distinguish between moves that draw on content knowledge and those that may draw on content knowledge. For example, moves that add to what students are saying in ways that clarify the connection between students' meanings and the discipline relied on content knowledge, whereas moves that connect students' ideas to one another may rely on content knowledge (or may rely on more superficial connections between student ideas, e.g., that students are referring to different objects). Our final analysis was coconstructed by both of us, enhancing the interpretive and theoretical validity of our account [107].

In conducting our analysis, our point is not to make a representative claim or to speak to the general need for particular facets of teacher knowledge about energy. It is to use in situ data to draw out and speak to a latent disagreement within the literature, and then to use these insights to inform teacher preparation. In other words, we do not expect particular moves to reproducibly draw on the specific content knowledge we identify-i.e., we do not expect the same moves to draw on the same content knowledge in different contexts. However, we do feel that our characterization of the role that teacher content knowledge can plays in responsive teaching-i.e., that the act of connecting students' ideas to one another and to the discipline can draw on teachers' content knowledge-is theoretically significant.

\section{EPISODES}

We present three episodes of responsive teaching that exhibit a range of responsive moves. Episodes 1 through 3 span grade levels-Sharon teaches third grade, Mark teaches eighth grade, and Alex teaches high school-and topics within energy - ranging from the energy in familiar objects to the energy in everyday scenarios to whether or not a girl on a swing loses energy as she picks up and then drops a backpack.

\section{A. Episode 1: Sharon and her students discuss energy in familiar objects}

Sharon teaches third grade in a West coast school where all students receive free lunch, and many are English language learners from a diversity of backgrounds. Leading up to episode 1, Sharon's class has been investigating the question, "How can you get a toy car to move?" One of Sharon's students (Kevin) suggested that "one way of stretching a rubber band" had more energy and so "could launch a car faster than another way of stretching the rubber band" [108]. Sharon asked her students to "help Kevin talk about how energy could be involved in the scenario." This launched an extended discussion of energy, with episode 1 taking place toward the end. In episode 1, Sharon has asked her students to write down their ideas about energy in their science journals, and some students approach Sharon to share their ideas with her.

At the beginning of the episode another student, Kervin, comes up to Sharon to share his idea that there is energy in a stretched rubber band and a ramp. Sharon brings out a rubber band for Kervin to look at and asks him a series of questions, such as, "How do I give this rubber band energy?" and "Okay, now, how does a ramp get its energy?" In response to this latter question, Kervin tells Sharon that the car on the less steep ramp "went faster." Sharon asks if that ramp "had more energy," and Kervin enthusiastically replies that it does because it had more time to gather up energy. Hopping back and forth, he shares his idea that the car rolling down the ramp gathers up energy like a snowball rolling down a hill gathers up snow. Sharon mirrors Kervin's excitement as she repeats Kervin's idea back to him, and she asks him to go and write it down in his science notebook.

Next, Tracy approaches Sharon to share her idea that energy means that you "can make it all the way to the finish line" when you are running a race. Sharon asks Tracy several questions that prompt her to describe her idea more, and then she facilitates a discussion between Tracy and Kervin. Tracy disagrees with Kervin's idea that the less steep ramp has more energy, instead arguing that a steeper 
ramp will have more energy. Sharon points out the disagreement between Kervin's and Tracy's ideas, and the two students discuss the conditions under which a ramp has more energy. Appendix A provides a full transcript of this discussion, and a video of parts of the discussion can be viewed in Ref. [108].

\section{B. Episode 2: Mark and his students discuss whether energy is involved in specific everyday scenarios}

Episode 2 comes from a small group discussion in Mark's eighth grade physical science class at an integrated suburban middle school in the Pacific Northwest. Prior to the start of the episode, Mark's students watched a movie that illustrates various everyday scenarios-a bus moving down the street, a bicycle being pedaled by a person, leaves blowing in the street, tree branches moving in the wind, a waving hand, a dropped racquetball, a clock, and a rolling basketball-and then broke into small table groups to discuss whether or not these scenarios "involve energy."

In the midst of their small group discussion, one group of five students (Ashley, Brianna, Christopher, Danielle, and Emily) calls Mark over to share a debate they have been having about whether there is energy involved in leaves blowing in the street. Central to their debate is whether moving leaves have energy, or just use energy from the wind. They seem to think the latter, but the students hesitate because they can think of other ways in which the leaves might have energy, such as their being alive or their being able to burn. The students, especially Brianna, seem to be "thinking out loud," and they alternate between playful frustration with one another and discussion and debate. After several minutes of discussion and debate, Mark introduces a new scenario - a ball rolling on the ground - and asks whether the ball would have energy. Christopher points out that someone would have to give the ball a push, which prompts Mark to change his scenario to a ball rolling down a hill, with no one pushing it. Would that have energy? Mark discusses this new scenario with the students for a short time and then he leaves the table without the students having come to a consensus. Appendix B provides a full transcript of this discussion.

\section{Episode 3: Alex and his students discuss the "Thalia on a Swing" question}

Alex teaches physics in a comprehensive public senior high school in the Northeast United States. Episode 3 is taken from a class discussion about the "Thalia on a Swing" question (Fig. 1).

The discussion about the "Thalia on a Swing" question began during the previous class session, so Alex starts by revisiting the ideas students have already voiced, summarizing that the students seem to be split between answer choices $\mathrm{C}, \mathrm{D}$, and $\mathrm{E}$. The discussion prior to the start of episode 3 centers on whether Thalia's speed will increase

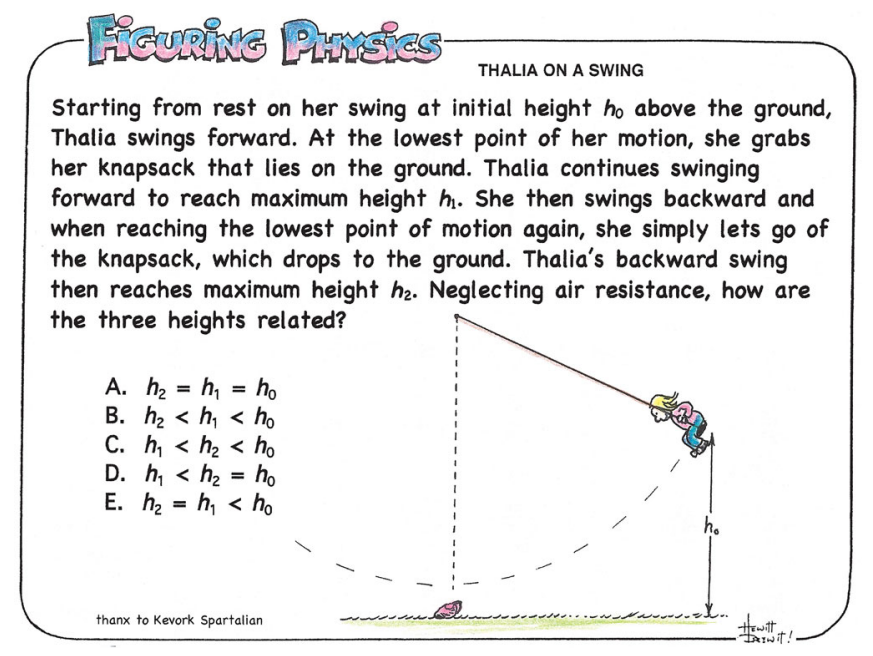

FIG. 1. "Thalia on a Swing" question. Reproduced with permission from Ref. [105], copyright 2009, American Association of Physics Teachers.

when she drops the backpack, because she is lighter, or will stay the same because acceleration due to gravity does not depend on the mass of the falling object. At the beginning of episode 3, Jason shares his thoughts about the energy involved, using the equation $\mathrm{U}_{\text {grav }}=m g h$ to reason that when Thalia picks up the backpack, her mass will be greater, so her height will be less, whereas when she drops the backpack her mass will return to the original quantity so she will swing up to her original height (choice D).

At this point another student, Nigel, proposes an alternate scenario in which a skateboarder ("Granny") is on a half pipe, and picks up a child ("Ambrose") at the bottom as she skates down. Nigel's idea is that Granny will slow down when she picks up Ambrose and thus not reach her original height, but she will be going faster on the way back down than she would if she were not holding Ambrose. With some prompting from Alex, Nigel articulates that Granny will get a boost when she lets go of Ambrose at the base of the half pipe, and from this information Alex infers that Nigel would say $h_{1}$ is lower than $h_{2}$. Based on Nigel's idea, Roy wonders how the backpack could put a force on Thalia when she drops it, which leads Roy to think that Thalia will actually lose energy when she drops the backpack.

As the discussion continues, Jason compares the scenario of (i) picking up and dropping the backpack to (ii) being handed and handing off the backpack. Students discuss the extent to which picking up or dropping the backpack changes Thalia's speed, and Alex proposes an alternate scenario for the class to think about: he suggests that the class imagine the backpack as an anvil that Thalia hands off to a three-year-old, and he asks if this new scenario "help[s the class] think about where the momentum is going over the course of the problem." A full transcript of episode 3 can be found in Appendix C. 


\section{ANALYSIS}

The moves made by Sharon, Mark, and Alex in episodes 1,2 , and 3 illuminate the role that a teacher's content knowledge can play in their responsive teaching practices. In particular, these teachers sometimes added to or extended student thinking in ways that we felt necessitated content knowledge. In other moments, the three teachers enacted responsive moves that could be construed as drawing on content knowledge, but we could also justify the teacher's response in terms of another form of knowledge; these instances more generally represent moves that may draw on content knowledge. In still other moments, the teachers enacted responsive moves that seemed to draw on knowledge or commitments of the type discussed in the literature (e.g., a commitment to listening), but we found no evidence that the teacher drew on content knowledge in responding to student thinking.

In this section, we give examples of instances in which the teacher's responsive move drew on or may have drawn on their content knowledge. In each case, we unpack the specific content knowledge brought to bear (or conceivably brought to bear) in making a particular move, in order to inform our sense of the role that content knowledge plays in responsive teaching. When possible, we situate each move in existing literature on responsive talk moves. We reserve discussion of moves that drew on forms of knowledge other than content knowledge for a separate section of the paper.

\section{A. Instances that draw on content knowledge}

Instances in which Sharon, Mark, or Alex drew explicit connections between what their students were saying or doing, or when they invited students to share their disciplinary ideas in open-ended ways, drew on these three teachers' content knowledge. More specifically, content knowledge played a role in their choosing examples that take up and clarify student thinking, in their organizing and revoicing student ideas in disciplinary terms, and in their asking open-ended questions that invited their students to think about energy in disciplinary ways.

\section{Choosing an example that takes up and clarifies student thinking}

In order to choose an example that clarifies or extends student thinking in ways that preserve its essence, the instructor must first attend to their students' ideas and notice the connections between these ideas and the discipline. This move is one type of Lau's [14] "building on student ideas," Levin's [12] "shifting the flow of classroom activity in a way that addresses [a student's] idea," and Pierson's [15] "uptake" ("students' ideas taken up through revoicing, expanding, clarifying, giving an ex[ample] or illustration"). There were two instances of teachers making this kind of move in the episodes we selected:
Mark, lines 68-70. In this snippet, Mark chooses an example that isolates the question his students have been grappling with: is it that leaves (and other moving objects) have energy, or is it that they use energy from an obvious source (e.g., the wind, gasoline, etc.)?

63. Christopher: Because when you just, like, press the pedal, the whole bus just, like, takes the gas, turns it into, like.

64. Brianna: Well it USES that energy (the gas has.)

65. Christopher: (So it uses YOUR energy) to make the bus move.

66. Mark: So are you saying the, the, like the gasoline is the energy?

67. Brianna: Yeah, the gasoline is the energy, and the bus USES the energy to power itself. Like, you know, the leaves use the wind to MOVE. And like we use, you know, whatever we have insides our bodies to FUNCtion and all that good stuff.

68. Mark: So what if, um, so go to like the, like, the rolling ball. So you see a ball rolling, uh, on the ground. Does that, does that have energy?

69. Christopher: Energy can't (go) on its own. Cause, like, you always, like, need a helper, and then, like, it goes.

70. Mark: So aside from, we know that, like, I gave it a push. But forget that. Like, (inaudible), we don't see anything pushing it. We just see it rolling. Or let's say, let's just say we set a ball on a hill. And it starts rolling down the hill. Does that ball have energy?

By taking away a visible energy source, Mark's proposed example takes up the students' question: can a moving object have energy, or does it just use energy (from a source)? In inventing this example, it seems that Mark uses content knowledge that energy is associated with motion: the feature that Mark's example highlights is the obvious energy source (or lack thereof), which suggests that he knows that the ball can still have energy even if it does not have a "fuel." The knowledge that Mark uses here is nuanced: it is not just knowledge that motion indicates energy, but an understanding of when kinetic energy is relevant, and that other forms of energy may be present in a scenario but not relevant to motion. This content knowledge is further evidenced by the fact that Mark modifies his example to a ball rolling down the hill to remove any implications of a push from someone or something.

Alex, lines 134-139. Leading up to the following snippet, Alex's students have been thinking about how the energy and momentum of Thalia will change, if they do at all, as she picks up a backpack at the bottom of her trajectory. Alex proposes a thought experiment that takes the concepts his students are thinking about to an extreme: 134. Alex: What have, let's see, what if we imagine the backpack as, as an anvil, a really heavy anvil, okay, and the person that's handing off the anvil and picking it up is, is a three-year-old girl. Okay? She's able to 
hold up the anvil and present it, as Thalia swings down and scoops it up off her hands. Now Thalia's swinging back down with the anvil ready to hand it off to the girl. What's gonna happen?

135. Student: She's gonna get knocked back.

136. Alex: She's gonna get knocked back, why?

137. Student: Because it has velocity (inaudible)...

138. Student: It has a lot of kinetic energy.

139. Alex: Does that, does that help us think about where the momentum is going over the course of the problem, or does that not help at all?

Since Alex asks if his change to the scenario helps the students to think about "where the momentum is going," it seems that he is choosing this example to draw out the students' ideas about how Thalia's momentum changes as she picks up the backpack. We see evidence that this move draws on Alex's knowledge that momentum is related to energy and that momentum is proportional to mass, since mass is the variable that Alex changes in order to help his students make sense of their debate.

To choose an example that takes up and clarifies student thinking, the teacher must first isolate a particular facet of the idea that students are grappling with, then choose a scenario or thought experiment that highlights that facet. It is likely that teachers draw on content knowledge in making this move because they must be able to see disciplinary ideas within students' statements, understand how they connect to each other, and choose an example that highlights the particular disciplinary concept that the students are (implicitly or explicitly) voicing.

\section{Organizing ideas and revoicing in disciplinary terms}

Unlike verbatim restatements of students' ideas, this move requires that the teacher synthesize the ideas and connect them to disciplinary concepts before revoicing the thought. We argue that such a move is responsive because it requires the instructor to understand the substance of students' ideas in order to select and sequence their revoicing of them, and because the teacher must refer back to students' ideas in the revoicing. This move encompasses other responsive moves discussed in the literature, including O'Connor and Michaels' [109] "revoicing," Pierson's [15] "uptake" (defined above), Lau's [14] "building on student ideas" in ways that preserve the student's original point or "interpreting student ideas," and Levin's [12] "rephrasing the idea." We give two examples in which Mark organizes his students' ideas around particular disciplinary facets of energy.

Mark, lines 12-14. Near the beginning of their discussion, Mark's students bring up the idea that leaves in the street move because of the wind, which is like a source of energy. Mark draws out a connection between these ideas and earlier ideas about energy sources for a bus or a bicycle.
8. Brianna: Cause we feel like, okay, a leaf has energy. It's a living thing, living things have energy. But are we talking about energy, like, in the fact that it moves? (And then, like, well) it needs wind to move it. The leaves in the street are just lying there basically. You can say it does because you need wind to move it? Wind is what, it doesn't.

9. (Danielle says something inaudible about the wind.)

10. Emily: Like, it has a source of energy.

11. Brianna: Yeah, it has a source of energy, but I mean, and it's, I guess you can say it's involved in energy because you can burn it and it emits flames, but I mean it's like, not, you know, in motion.

12. Mark: So it sounds like you guys are saying, it sounds like you guys are saying a number of things. So first off, going back to the bus and the bike, you said that they have kind of a source of energy.

13. (Students agree.)

14. Mark: And so since they have a source of energy, they were doing something? Is that?

In his response to Brianna in lines 12 and 14, Mark organizes several things the students have said (e.g., leaves need a source of energy to move; buses and bicycles have sources of energy in gasoline and people), around a generalizable disciplinary concept that connects their ideas: "doing things" requires energy. He does more than restate Brianna's and Emily's ideas, he connects them causally: the source makes the action possible. In making this generalization, we infer that Mark uses content knowledge that motion requires energy, and that energy must come from somewhere (i.e., energy is conserved). This content knowledge helps him interpret the students' implicit questions as being about motion requiring energy, and it helps him see how the ideas they share about sources of energy are related to their question.

Mark, line 36. Leading up to the following snippet, Mark's students are discussing whether leaves sitting in the street have energy, as compared to leaves moving in the street. Emily brings up an alternative way in which the leaves might have energy - they're alive — but Christopher argues that the leaves (which have fallen off the tree) do not have energy ("they're dying"), and Brianna disagrees:

25. Emily: Well, wait, with the leaves on the ground, though, technically, are they still alive?

26. Brianna: Yeah, they are still alive but they're not moving.

27. Emily: Are they still, like, growing?

28. Brianna: No, they're not growing.

29. Christopher: (They don't have energy, they're dying)

30. Brianna: Leaves on the ground don't grow. They're dying.

31. Danielle: (inaudible) they're off the tree.

32. Christopher: So they do not have energy.

33. Brianna: But they do have energy because you can still use leaves on the ground to burn something. 
34. Danielle: You can burn anything.

35. Christopher: Uh, no but if you're (inaudible).

36. Mark: So that's an indicator to you, evidence for you is that if something is, if we can burn something, that means it must have had energy.

In line 36, Mark revoices what Brianna says, but instead of repeating her words he rephrases them to highlight burning as "an indicator" or "evidence" of energy. Because Mark uses such terminology, we infer he is drawing on knowledge that burning is evidence of energy. Mark's statement is also more general than what Brianna said: it is not just that leaves have energy if they can burn; it is that things that can burn have energy. Because Mark generalizes Brianna's idea and foregrounds the concept of indicators or evidence of energy in his restatement, we infer that Mark uses knowledge that perceptible indicators evidence the presence of energy. This content knowledge would allow him to see that burning is a particular kind of evidence and pick this idea out as a productive direction to highlight.

When organizing students' ideas and revoicing them in disciplinary terms, a teacher takes what a student says and repeats it back in a way that explicitly connects what students mean to disciplinary terms or concepts. Doing so draws on content knowledge-the teacher must see this connection, and then she revoices it in terms that reflect the idea's disciplinarity.

\section{Inviting students to think about energy in a disciplinary way}

A specialized form of Brodie's [22] "elicit," inviting students to think about energy in a disciplinary way is characterized by open-ended questions that invite students to share their ideas and at the same time center the discussion on disciplinary concepts. While this move does elicit particular kinds of ideas, these questions do not have only one correct answer, and the teacher does not evaluate the students' responses. Although these questions are still open ended and invite students to share their thinking, they differ from the general invitations to elaborate such as "why" or "tell me more," because they focus students' thinking on a particular topic. We illustrate this move with two instances from Sharon's classroom:

Sharon lines 1, 5, 20, and 36. In this series of questions, Sharon invites her students to think about the nature of energy:

1. Sharon: Okay, now how can I give this rubber band energy?

5. Sharon: ... Show me how you're gonna give this rubber band energy?

20. Sharon: Okay, now how does a ramp get its energy?

36. Sharon: How do you get it? How do you get it? Your energy?

These questions invite students to think about a particular facet of energy, that is, where it comes from. Because
Sharon repeatedly asks her students where energy comes from, we infer that she knows that energy is conserved and transfers between objects. Moreover, we infer from the emphasis that Sharon puts on this idea that she knows energy conservation and transfer can explain many phenomena.

Sharon lines 42-44. Here, Sharon asks a question that both connects two students' ideas and invites them to think about the nature of energy:

38. Sharon: Okay, so Kervin, Tracy told me that energy is like when you're running, you can make it to the finish line. Could you show Tracy what you thought of energy as?

39. Kervin: As what? In the rubber band?

40. Sharon: In the rubber band, ya.

41. Kervin: Okay. Like, if you sometimes, if you stretch it, okay a little bit loose because it's going to break, if you sometimes.

42. Sharon: So do you think that that's energy too? You do? Are they the same? They are? That's the same kind of energy?

43. Tracy: Sort of.

44. Sharon: Sort of? What about when Kervin was talking about how the ramp had energy is that the same? No? Why not?

Sharon's questions in lines 42 and 44 focus on whether energy in a rubber band and in a runner are the same kind of energy. This suggests Sharon is using knowledge that energy can take different forms.

Teachers making this move ask open-ended questions that center around key disciplinary concepts, which seems likely to draw on a teacher's content knowledge, including the ways that this knowledge is organized in the discipline. Content knowledge supports teachers in choosing questions that invite their students to share their thinking about central aspects of a concept, in this case energy, at times when they cohere with the flow of the conversation.

\section{B. Instances that may draw on content knowledge}

Instances in which Sharon, Mark, and Alex connected students' ideas to one another or inferred a student's answer to a question could be explained by the teacher's use of content knowledge, or they could be understood in terms of other knowledge, such as knowledge of student ideas or superficial similarities between students' answers. In each case, we describe both possible interpretations of the teacher's knowledge in use, and we argue that these moves more generally may draw on content knowledge. Because our aim is to understand the role(s) of content knowledge in responsive teaching, it is less important for us to conclusively establish whether or not each move relied on content knowledge. More important is to understand the role that content knowledge played supposing that the move did rely on content knowledge. 


\section{Connecting students' ideas to one another}

In Episodes 1-3 there are several different ways in which teachers connect students' ideas to one another. Such moves are responsive if the teacher makes a substantive connection between students' ideas-i.e., a connection that ties together the essence of what two students are sayingbecause it preserves the meaning of students' ideas and encourages them to collaboratively make sense of their ideas. This move also encompasses several responsive moves described in the literature: Lau's [14] "noting differences between students' ideas," Lau's [14] "calling the class' attention to a student's idea," Brodie's [22] "maintain" ("maintain[ing] the [student's] contribution in the public realm for further consideration"), Richards' [45] "identifying similarities between students' ideas," and Pierson's [15] invitations to "make sense of others' ideas." We see several ways in which Sharon, Mark, and Alex connect student ideas, some of which seem to draw on content knowledge and some of which do not:

Sharon, lines 39-42. Two students, Tracy and Kervin, individually share what they think energy is. Sharon connects the two ideas by repeating Tracy's idea about energy (lines 30-36: "Ms. F-, I know what energy is for the people running...Um, energy is like you can make it all the way to the finish line.") and asking Kervin to explain the idea he had shared earlier:

39. Sharon: Okay, so Kervin, Tracy told me that energy is like when you're running, you can make it to the finish line. Could you show Tracy what you thought of energy as?

40. Kervin: As what? In the rubber band?

41. Sharon: In the rubber band, ya.

42. Kervin: Okay. Like, if you sometimes, if you stretch it, okay a little bit loose because it's going to break, if you sometimes.

In repeating Tracy's idea and asking Kervin to share, Sharon may be pointing to superficial differences in the students' statements (energy is in a rubber band vs energy is making it to the finish line) or differences in underlying concepts (energy is stored in objects vs energy is associated with movement: different forms of energy). Since Sharon does not say anything regarding how these two ideas are different and she does not add to the students' statements, there is no clear evidence that she is drawing on her knowledge of different forms of energy here. However, we do have evidence that Sharon is inviting her students to engage in the scientific practice of sharing and debating different models.

Alex, lines 68-69. Like Sharon, Alex invites his students to compare their ideas. In the exchange leading up to line 68, Roy questions whether or not Thalia speeds up when she drops the backpack at the bottom of her swing, and Alex notices a connection between Roy's line of thought and something that Jason said earlier in the discussion: in lines 2-14, Jason argues that if Thalia does not lose energy, he can use the equation for gravitational potential energy$m g h$ - to solve for Thalia's height.

68. Roy: And so now we don't have to solve for $m g h$ again or $1 / 2 m v^{2}$ because we don't have the same amount of kinetic energy, or the amount of energy that we started at the beginning with.

69. Alex: Okay, so this seems to be addressing Jason's question, and Jason said if he could show that the energy was always the same, then $\mathrm{D}$ would be the correct answer. And you seem to think that the energy is not the same.

In line 68, Roy is saying that he cannot solve for potential or kinetic energy after Thalia drops the backpack, because she slows down when she picks the backpack up, which means that she does not "have the same amount of... energy that we started at the beginning with." At a surface level, Jason's and Roy's ideas are connected because they have to do with whether or not the energy of the system changes during the scenario and with the equation for gravitational potential energy. It is also possible that Alex uses content knowledge that changing the energy at the bottom of the swing (what Roy is thinking about) will also change the height that Thalia swings to (what Jason was thinking about). Knowledge that energy is conserved and an understanding of the relevant systems (i.e., Thalia, or Thalia and the backpack) would allow Alex to understand Roy's argument that the kinetic energy changes at the bottom and connect it to Jason's argument about how not changing the total energy would affect Thalia's final height.

Alex, lines 96-101. Later in the discussion, Alex responds to Jason by connecting his ideas back to something Geoff said:

96. Jason: The backpack's falling because the gravity's pulling it, not because she gave it energy to make it fall.

97. Alex: Okay, so Geoff, was Geoff's point-

98. Student: (inaudible)...

99. Alex: All right, back to Geoff's point that the backpack falls, Jason has an issue with the backpack falling, was that your point, Geoff, that the backpack falls?

100. Geoff: No, my point was the backpack has the same speed, it does not, the backpack does not lose speed when she lets it go.

101. Alex: Okay, so Geoff's point I think wasn't that it fell, it has some velocity this way [horizontally], and if there were, depending on how far away the ground were, the backpack's gonna fall in a parabola to the ground, but it's not so much the falling that Geoff is concerned with, it's that this [horizontal] velocity he's concerned with.

In this excerpt and in the previous lines, Jason argues that the energy associated with the motion of the backpack as it falls comes from gravity, not from Thalia. Alex remembers 
that Geoff had said something about the backpack falling earlier in the conversation ${ }^{5}$ :

(i) Geoff: So they're saying the, the mass, you, you transferred your velocity, you had a momentum when you were coming down, you kept the momentum when you were going up because you have a higher mass but slower velocity, so you're saying when you get a lower mass you'll have a higher velocity?

(ii) Alex: That, that seems to be what they're saying, yes.

(iii) Geoff: So, yeah, but when you picked up the backpack, it wasn't moving. When you let it go, it doesn't drop straight down, it keeps moving, okay, it keeps its velocity.

(iv) Nigel: But that wouldn't stop your speed-

(v) Jason: It doesn't say that.

(vi) Nigel: If the backpack is moving that way (points left), it wouldn't stop your speed.

(vii) Geoff: If you threw it, if you threw it back so it would like, when you're, when you're walking and you drop it, or if you're in a plane and you drop it, it'll keep going with you until it hits the ground, it doesn't, it doesn't go to a velocity of zero as soon as you let go of it. It keeps its speed.

(viii) Nigel: But that's-

(ix) Geoff: It's not losing any, the backpack is not losing any velocity

Just before this snippet, some students had proposed that Thalia would speed up when she dropped the backpack, citing conservation of energy and arguing that since her mass would be less, her velocity would be greater after the drop. Here, Geoff argues that the backpack continues to move when it is dropped, suggesting that momentum would be conserved without Thalia speeding up. Alex initially connects Jason's and Geoff's ideas through the shared idea of the falling backpack (lines 97 and 99). In order to interpret Geoff's point in connection with Jason's in line 101, Alex could be using knowledge that if the backpack continues to move horizontally when Thalia lets go, the backpack must have kinetic energy at the instant Thalia lets it go, such that Geoff's argument would counter Jason's argument that the energy comes from gravity. However, it is unclear whether Alex is making a connection between the students' ideas at this level or simply connecting them because they have to do with the backpack falling.

On the basis of this analysis, we suggest that content knowledge seems to play a role in connecting students' ideas when the connection that the teacher makes is based on the scientific concepts that underlie the students' ideas. For example, the teacher may be drawing on content knowledge to connect students' ideas to disciplinary concepts, and then to understand similarities and differences

\footnotetext{
${ }^{5}$ These lines of transcript are taken from a part of the same discussion in Alex's class that occurs before our selected episode.
}

between students' ideas based on those underlying disciplinary concepts. It is less clear that content knowledge plays a role when the connection between student ideas is superficial-e.g., when teachers draw out differences in the objects students are comparing.

\section{Inferring a student's answer}

As Alex discusses the "Thalia on a Swing" question with his students, he sometimes infers their multiple choice answer based on the ideas they express. We argue that this move is responsive because in order to reasonably infer a student's answer, Alex first must understand the student's own meaning behind what they say. In connecting the students' ideas back to the original question, Alex focuses the conversation in a way that preserves the essence of students' ideas. This is an original category of teacher move but could be interpreted as one form of Lau's [14] "interpreting student ideas."

In lines 16-34, Nigel uses the example of "Granny and Ambrose on the half pipe" to think about how Thalia's speed will change when she drops the backpack. Nigel explains that when Granny picks up Ambrose (we assume at the bottom of the half pipe), she slows down, and will continue to slow down until she reaches a maximum height that is lower than the height at which she started:

16. Nigel: All right, my way of thinking about it is I went back to Granny and Ambrose.

17. Alex: Granny and Ambrose, yes, go back to Granny and Ambrose!

18. Nigel: All right, so we concluded that when she was rolling, right, and she picked him up-

19. Alex: Yeah.

20. Nigel: She lost speed.

21. Alex: She lost speed, absolutely.

22. Nigel: All right, so I'm thinking in my head, okay, so she would lose speed which means that her distance would not be as far as if she had just let him go.

23. Alex: Okay.

24. Nigel: All right? So I was picturing, let's say she's on a half pipe.

25. Alex: All right, let's say she's on a half pipe, sure.

26. Nigel: I'm trying to (inaudible)...

27. Alex: All right, Granny and Ambrose on the half pipe!

28. Nigel: All right, so she's at the top, right?

29. Alex: Yep.

30. Nigel: She picks up Ambrose.

31. Alex: Yep. (acting this out)

32. Nigel: She's slowing down the whole way until she gets to a certain point-

33. Alex: Okay.

34. Nigel: Which is lower than where she started.

35. Alex: That's right.

After a brief interruption from a student who challenges his reasoning, Nigel moves on to thinking about what will 
happen in the hypothetical situation that Granny rolls back down the half pipe and lets Ambrose go:

44. Nigel: All right, so when she gets back down, she lets Ambrose go.

45. Alex: Lets Ambrose go, okay.

46. Nigel: She's still moving, but she'll be moving-I lost it, damn I lost it!

47. Alex: When she lets Ambrose go, does she get a boost? Or does she just keep going at her same speed? Or something different? Does she slow down when she lets Ambrose go, does she continue at the same speed when she lets Ambrose go, or does she get a boost by letting Ambrose go?

48. Nigel: A tiny boost because now her mass is less and her velocity would be more because-

49. Alex: Okay, so you would be in the camp that seems to argue $\mathrm{H}_{1}$ is small but then $\mathrm{H}_{1}, \mathrm{H}_{2}$ goes back to being big.

Alex hears Nigel saying in lines 16-34 that less speed means less height- -"so we concluded that when...she picked him up...she lost speed...She's slowing down the whole way until she gets to a certain point... which is lower than where she started."-and then in line 48 that he thinks Granny will get a boost by letting Ambrose go. Alex infers that since Nigel thinks that Granny is moving faster when she releases Ambrose, Thalia would also be moving faster when she releases the backpack, and thus she will swing higher, so Nigel would say that $\mathrm{H}_{2}$ is greater than $\mathrm{H}_{1}$. When Alex makes this inference, he could be drawing on content knowledge that Thalia's speed at the lowest point is related to her kinetic energy, that her height at the highest point is related to her potential energy, and that energy conservation dictates that more speed at the bottom of the trajectory will mean more height at the top. On the other hand, Alex could simply be following Nigel's thought pattern of slower means lower (in lines 16-34) to say faster means higher. Because it is unclear how Alex infers Nigel's answer, it is also unclear whether this move draws on content knowledge.

Generally speaking, in order to infer a student's answer to a particular problem, a teacher must use a chain of reasoning that is either based on something that the student previously said or based on the teacher's own knowledge of the concepts that underlie the student's idea.

\section{DISCUSSION}

\section{A. What role(s) does content knowledge play in responsive teaching?}

In our analysis, common to all of the moves that clearly drew on a teacher's content knowledge was an effort to make disciplinary connections within and between students' ideas. For example, in Brianna's, Emily's, Christopher's, and Danielle's wonderings about the various ways in which leaves blowing the street might have energy - because they're moving, because they're alive, or because they can burn-
Mark saw the association between energy and indicators, and he organized and revoiced their thinking to highlight this. And Sharon asks targeted but open-ended questions about energy to give her students opportunities to make these connections themselves. It seems, then, that one role that content knowledge plays is to support teachers in eliciting, seeing, and then pursuing these disciplinary connections within their students' thinking. A similar role was served in those moves that may have drawn on Sharon's, Mark's, or Alex's content knowledge. If these moves drew on content knowledge, this knowledge supported teachers in making substantive connections between ideas, as in Alex's seeing how the substance of one student's idea would challenge another's, or in connecting a student's line of thinking to the overarching question at the center of the class' discourse.

Although our analysis is limited to three short episodes, the teachers in these episodes instantiate more general responsive moves, and the moves themselves seem to rely on content knowledge. In other words, it is not just that Mark's organizing and restating in disciplinary terms draws on content knowledge; the move itself seems deeply tied to knowledge of the content. Even more generally, seeing and pursuing disciplinary connections within and across students' ideas seems to necessitate knowledge of the discipline - be it content or practices - and this bears out not only in our analysis but also in the quotes from practitioner accounts we cite in the Introduction. Which brings us to this following point: our analysis highlights the intellectual rigor of the kind of responsive teaching that authors like Ball, Atkins, and Frank, and Hammer describe in their personal reflections. This teaching is more than "observational listening," or "listening with an attempt to hear the child's thinking but with nascent formulations about what is heard and few active attempts to support or extend that thinking" [43]. It is more than an "anything goes" and "everything's great" approach to instruction; it involves thoughtfully and flexibly using multiple forms of knowledge and expertise, including content knowledge, to extend and refine the nascent science in what students are saying and doing.

It may also be the case that responsive teaching draws on different kinds of content knowledge than more traditional forms of teaching. Though not the focus of this investigation - and though more extensive analysis of more cases would be necessary to substantiate a claim-we notice that the content knowledge that Sharon, Mark, and Alex used in responding to their students' thinking includes ideas like energy conservation, energy forms and indicators, and the dependency of energy on mass. The nature of these ideas is that of the basic "building blocks" of physics, so to speak, rather than, for example, concepts that are covered in more advanced university courses (e.g., entropy, free energy, dissipative forces). For example, when Sharon asks Kervin and Tracy whether the energy in a rubber band and the energy in running are the same kind of energy, she 
draws on knowledge that energy can take different forms, and she does so in response to the ideas that came up in conversation. When Alex and Mark pose examples to extend their students' thinking, they draw on knowledge of the disciplinary concepts that underlie the student ideas they intend to target - that objects in motion do not need an obvious source and that energy and momentum depend on mass, respectively. Each of these represents foundational knowledge about energy, used in a way that is flexibly tied to student thinking. This makes sense, given the role we articulate in the previous sub-section; we would expect that connecting students' ideas to one another and to the discipline would involve knowledge that ties together many different ideas and physical scenarios. Pursuing this question in depth could be the subject of future analysis.

Finally, our examination of the relationship between content knowledge and responsive teaching —including both our foray into the literature and our case studies - motivates additional questions about the depth and the scope of the content knowledge required to teach responsively. Answering this question would require more extensive analysis with larger numbers of teachers, which is beyond the scope of this exploratory study. However, our work provides a working research methodology for future explorations of this question. In particular, for each snippet we analyzed, we illustrated how we (i) characterized the responsive move made by the teacher, (ii) identified evidence of teacher content-knowledge in use, and (3) examined ways and the degree in which the responsive move relied on the content knowledge we identified. Others may wish to use similar methods to answer questions about the intersection between teacher knowledge and responsive teaching practices.

\section{B. What other forms of knowledge and commitments are brought to bear in responsive teaching?}

Though not the focus of our analysis, there were instances in which Sharon's, Mark's, and Alex's responsive moves seemed not to rely on content knowledge but instead to rely on other forms of knowledge, commitments, or dispositions. For example, Mark regularly invited students to elaborate on their ideas without narrowing the scope of how to do so, using statements such as "tell me more" and questions like "Why?" In lines 54-62, Mark exemplifies this practice as he tries to understand what energy indicates for his students:

54. Mark: So, I, I wanna come back to, aside from the issue of kind of living versus dead, (does that burn), aside from that, I wanna go back to the motion issue. So how do we, how do we figure this out? I mean, so if the leaves don't move without the wind, does that mean the leaves don't have energy?

55. Brianna: No.

56. Mark: Why?

57. Brianna: Well, because, the bus, you know.

58. Mark: So the bus has energy because it was...
59. Brianna: Well, does it have energy, or does it just use energy? I mean, it's, it's a metal thing! It's a thing! Metal.

60. Christopher: The bus has the energy to use energy.

61. Emily: But doesn't everything like use energy?

62. Mark: (To Christopher) What do you mean by that?

By asking "Why?" in line 56, Mark invites Brianna to explain why she thinks the leaves might have energy even if they do not move without the wind, and he does so without confining her explanation to any particular content-Brianna is free to express whatever reason she has for stating what she did. This responsive move serves the dual purpose of helping Mark to better understand Brianna's line of reasoning and encouraging Brianna to make sense of her thoughts by giving an explanation. Mark makes a similar move in line 62 when he elevates Christopher's claim (line 60), asking him, "What do you mean by that?" Mark's question does not reference specific energy concepts or demonstrate interpretation of Christopher's statement, so there is no evidence that Mark is using content knowledge in asking for clarification. Both moves do seem to indicate Mark's commitment to fully understanding his students' thoughts.

Similarly, responding to student affect, as Mark does in the example below, does not obviously draw on a teacher's content knowledge. Jaber and her colleagues have argued that part of attending to students' thinking is noticing and responding to their affective experiences $[60,110,111]$. We see Mark making this kind of move, for example, in line 51: 48. Brianna: Well, I'm saying, you can! (Laughing) You can burn dead things, and they don't have energy and yet you seem to get these flames.

49. Christopher: Are you going against your own?

50. Brianna: Yes, I am! So shush you! I'm working it through in my mind!

51. Mark: That's good. I like that.

In this instance, we might infer that Mark is committed to encouraging his students' efforts to try out and make sense of different ideas, or that he recognizes productive metacognition at play in this moment. Similar to Mr. James in Jaber's analysis of a fifth-grade classroom interaction, Mark's "praise was at once an affective repair and an epistemological move to reaffirm the value of attending to and offering ideas and persisting in the face of an intellectual challenge" [110]. This move did not appear to depend on Mark knowing anything about energy, and we do not have evidence of Mark's drawing on content knowledge to do so.

In general, these two responsive moves-inviting students to elaborate with general questions and responding to students' affect-point to knowledge and commitments other than content knowledge. The former may draw on teachers' commitments to listening to and understanding their students, or on teachers' general epistemological 
understanding that constructing evidence-based arguments is an important part of knowledge construction in science. And it is possible that a teacher's responding to affect would draw on knowledge of what it means to "feel like a scientist"- those affective experiences that advance and sustain scientific pursuits, such as "taking pleasure in phenomena," "empathizing with the object of study," and persisting in the face of intellectual challenges [111].

These findings corroborate the recommendations of the responsive teacher education literature-responsive teaching does entail a commitment to listening and epistemological knowledge, among other things, and the moves served by this knowledge and these commitments are important to the culture and practices of a scientific classroom community. Further, epistemological knowledge and commitments to listening and understanding their students serve teachers in our earlier examples in which teachers were also bringing content knowledge to bear; it is not as though, for example, content knowledge serves one set of moves and epistemological knowledge serves another set. This interconnectedness informs our suggestions for future work with teachers, which brings us to the next section.

\section{IMPLICATIONS FOR RESEARCH AND TEACHER EDUCATION}

Altogether, our work suggests that the role of content knowledge in supporting the enactment of responsive teaching is more nuanced than "it does" or "it does not." We opened this paper with a discussion of the latent disagreement about content knowledge in responsive teaching - whereas Wallach and Even [25] claim (and others imply) that content knowledge can overfilter teachers' listening and responsiveness to students' ideas, other accounts of RT [26,27,80] imply its necessity for rigorous RT. In arguing here that content knowledge supports teachers in seeing and pursuing disciplinary connections within and across students' ideas, we are not claiming that Wallach and Even are wrong; certainly content knowledge can constrain RT. However, it can also support it, in the ways we articulate. Which leads us to ask the question, "How can we support teachers in developing content knowledge in such a way that it enhances their attention and responsiveness to student thinking?" And, relatedly, "How can we capitalize on the collective wisdom of the physics education research community in preparing responsive physics teachers?"

In response to the first question, we suggest that teacher education focus both on development of teacher content knowledge and on using that knowledge to intentionally practice attending to, identifying the disciplinary productivity of, and responding to student thinking. This could be done in simulated environments such as video clubs or in situated professional development in real-time instructional settings. In other words, just as recent STEM education reforms focus on students developing content knowledge in ways that are integrated with scientific or mathematical practices, we suggest that teachers develop content knowledge alongside and integrated with responsive instructional practices. Exclusive focus on the development of content knowledge may contribute to the overfiltering that Wallach and Even warn us about, whereas exclusive focus on developing instructional practices may promote a view of teaching as "observational listening" [43].

In response to the second question, our sense is that teacher education within physics education research (PER) [83-89,112] has focused extensively on developing teacher content knowledge - aligned with research in the tradition of pedagogical content knowledge (or content knowledge for teaching) [113-116] — and less on practice in attending and responding to the "seeds of science" in student thinking. 6 Though we are issuing a recommendation (above) to physics teacher educators to shift toward a more integrated approach to teacher education, we also feel that the field of science teacher education more broadly can benefit from the collective wisdom of the PER community in considering how to support teachers in developing rich, robust physics content knowledge. In our efforts to synthesize across PER-driven teacher education efforts for this paper, we found surprisingly little in the literature documenting what is happening, teacher-education wise, in our field. This is not because our field is not doing this work; we know from conference presentations and hallway discussions that there are wellestablished and ongoing efforts in physics teacher education. Thus, we close with a call to our physics teacher education colleagues: let's get the word out, both within our field and beyond, about what we know about teacher learning of physics content. As reforms push STEM teacher education to prepare instructors who are "both responsive to students and responsible to [the discipline]," we need to be talking about how to support teachers in doing each of these, and then doing them together. Our hope is that our work can provide a foundation from which a conversation about preparing teachers to be both responsive and faithful to the discipline of physics can proceed.

\section{ACKNOWLEDGMENTS}

This material is based upon work supported by National Science Foundation Grant No. DRL-122732. We are indebted to Fred Goldberg, Daniel M. Levin, and Jennifer Richards for providing video and transcripts from Sharon's and Alex's classrooms and to the National Science Foundation Grants that supported their work (No. NSF DRL-0732233, No. NSF DRL-0733613, and No. NSF DRL-0455711). We also gratefully acknowledge the thoughtful feedback offered by members of the PER@SPU research team, including Abigail R. Daane,

\footnotetext{
${ }^{6}$ One exception is the model proposed in the under review paper, "Organizing Teacher Professional Education around Productive Habit Development: A Way to Meet Reform Challenges," by Etkina, Gregorcic, and Vokos.
} 
Lezlie S. DeWater, Sarah B. McKagan, Rachel E. Scherr, Lane Seeley, and Stamatis Vokos; by members of the "teacher responsiveness video club," including Andrew Elby, Melissa J. Luna, Jennifer Richards, Rosemary S. Russ, and Janet Walkoe; and by three anonymous reviewers.

\section{APPENDIX A: FULL TRANSCRIPT FROM SHARON'S CLASS}

Throughout this transcript, parenthetical references indicate nonverbal utterances.

1. Sharon: Okay, now how can I give this rubber band energy?

2. Kervin: Well, you just pull it back.

3. Sharon: Go ahead and do it.

4. Kervin: Test it out?

5. Sharon: No, ya. Show me how you're gonna give this rubber band energy?

6. Kervin: Like this, look (pulls it back).

7. Sharon: So where, can you use your other hand now and show me where the energy is?

8. Kervin: Right, um, right here (points to center of rubber band where he is pulling back.)

9. Sharon: So there's energy right there. And what's that going to do?

10. Kervin: It's gonna push it more, more, um, more forward and more faster.

11. Sharon: Okay, could you give this rubber band even more energy than that? Is that possible? What would I do to do that?

12. Kervin: You have to go like farther to give it energy.

13. Sharon: Pull it back even farther? And um, Kevin was saying that if I stretched it this way, it gave it more energy (stretches it longways). Is that true?

14. Kervin: Yes, and if you pull it back like far too (pulls it back towards him).

15. Sharon: So now that's even more energy?

16. Kervin: Yes.

17. Sharon: So the way that I give this energy is by stretching it either this way or backwards?

18. Kervin: Yes.

19. Sharon: Okay, now how does a ramp get its energy?

20. Kervin: Easy, it needs to be like all the way here, like last time.

21. Sharon: (side conversation with another student).

22. Kervin: Like last time we did three ramps, number 1 , number 2 , number 3 . Number 2 went the fastest because it was lower, so a ramp, if it's lower, it goes faster.

23. Sharon: So does it have more energy?

24. Kervin: Yes, because it has more time to gather up the energy.

25. Sharon: So when it's rolling down the ramp, it's gathering up energy?

26. Kervin: Yes, like a snow ball.
27. Sharon: Like a snow ball. How it gathers up snow but it's just gathering up more and more and more energy?

28. Kervin: Yes.

29. Sharon: Could you write that down for me so I could have that to remember and share with other people?

(At this point, Sharon has a brief conversation with another student about his ideas about energy. We have chosen to omit this section because it is unrelated to the larger conversation.)

30. Tracy: Ms. F-. I know what energy is for the people running.

31. Sharon: Tell me?

32. Tracy: Um, energy is like you can make it all the way to the finish line.

33. Sharon: So energy means that you make it to the finish line?

34. Tracy: You can make it everywhere you want to go. That's what energy is.

35. Sharon: How do you get it? How do you get it? Your energy?

36. Tracy: Just if you're jogging and jogging and jogging and there's still a lot of energy left in you. Then if you get tired maybe rest for five minutes then you will have all of your energy back up.

37. Sharon: Okay, so Kervin, Tracy told me that energy is like when you're running, you can make it to the finish line. Could you show Tracy what you thought of energy as?

38. Kervin: As what? In the rubber band?

39. Sharon: In the rubber band, ya.

40. Kervin: Okay. Like, if you sometimes, if you stretch it, okay a little bit loose because it's going to break, if you sometimes.

41. Sharon: So do you think that that's energy too? You do? Are they the same? They are? That's the same kind of energy?

42. Tracy: Sort of.

43. Sharon: Sort of? What about when Kervin was talking about how the ramp had energy is that the same? No? Why not?

44. Tracy: Well, actually it is because you can run down the ramp and the car could go down the ramp too.

45. Sharon: Okay. Does that, and Kervin was saying that it's like a snowball. If the ramp is nice and low, it picks up a lot of energy as it goes?

46. Tracy: Sort of, if you make it a little bit higher.

47. Sharon: Oh so you think it gets more energy if it's higher?

48. Tracy: Ya.

49. Sharon: So you guys disagree.

50. Kervin: I don't disagree with her.

51. Sharon: No, you do disagree with her, you do, you just weren't listening. She-you think that it has more energy if it's lower.

52. Kervin: Yes, because. 
53. Sharon: But sweetheart, she says it has more energy if it's higher up. So you do disagree.

54. Kervin: Yes, I do, but if it's too steep, it will just crash into the bottom, but if it's low, like ramps number 1 , number 2, number 3, it will...it will go down faster.

55. Timmy: Energy is rolling too. For the snowball, energy is rolling like rolling around.

56. Sharon: Okay, so that one has the most energy when it's on the top? Can you go write all that down?

\section{APPENDIX B: FULL TRANSCRIPT FROM MARK'S CLASS}

Throughout this transcript, capitalized text denotes speaker emphasis. Parenthetical references indicate nonverbal utterances or ambiguities in our transcription.

1. Brianna: Mr., Mr. James, we're having a pretty hard decision on three of these.

2. Danielle: Well actually just two of 'em.

3. Brianna: Two. Leaves in the street and tree branches.

4. (Danielle says something at the same time, but it is inaudible)

5. Mark: Kay.

6. Brianna: So our argument, we feel like it is and it's not.

7. Mark: Kay.

8. Brianna: Cause we feel like, okay, a leaf has energy. It's a living thing, living things have energy. But are we talking about energy, like, in the fact that it moves? (And then, like, well?) it needs wind to move it. The leaves in the street are just lying there basically. You can say it does because you need wind to move it? Wind is what, it doesn't.

9. Danielle says something about the wind.

10. Emily: Like, it has a source of energy.

11. Brianna: Yeah, it has a source of energy, but I mean, and it's, I guess you can say it's involved in energy because you can burn it and it emits flames, but I mean it's like, not, you know, in motion.

12. Mark: So it sounds like you guys are saying, it sounds like you guys are saying a number of things. So first off, going back to the bus and the bike, you said that they have kind of a source of energy.

13. (Students agree.)

14. Mark: And so since they have a source of energy, they (were doing) something? Is that?

15. Mark: So the leaves?

16. Brianna: Had a source of energy that moves, had a source to move. But, I mean, like.

17. Mark: Tell me about movement. What does movement have to do with it?

18. Brianna: Well, we were saying because here it says objects in motion (and they need) energy to like, to move, to continue going.

19. Mark: So it's not necessarily that an object that is moving HAS energy, it just takes energy to cause something TO move?
20. Brianna, Danielle: Yeah. Yes.

21. Mark: Is that?

22. Brianna: That's what we thought with the bike and the bus, you know. And it takes energy to MOVE it, but like, a leaf HAS, I feel like, yeah, if we use that definition, then I guess, you know, leaves in the street.

23. Mark: So I think we can, I think there's maybe a couple different things we can look at. There's like, okay, so, yu- you guys saying kind of living things have it. So like the leaf because it's living thing has energy. So that's like one reason you could say yes. But you're saying that the, aside from that, the leaf does not have energy, is that right?

24. Brianna: Yeah. Because wind, but then again, she made the point that, you know, a bus doesn't move without the gas and the bicycle doesn't move without the person pedaling it, so.

25. Emily: Well, wait, with the leaves on the ground, though, technically, are they still alive?

26. Brianna: Yeah, they are still alive but they're not moving.

27. Emily: Are they still, like, growing?

28. Brianna: No, they're not growing.

29. Christopher: (They don't have energy, they're dying?)

30. Brianna: Leaves on the ground don't grow. They're dying.

31. Danielle: (inaudible) they're off the tree.

32. Christopher: So they do not have energy.

33. Brianna: But they do have energy because you can still use leaves on the ground to burn something.

34. Danielle: You can burn anything.

35. Christopher: Uh, no but if you're (?).

36. Mark: So that's an indicator to you, evidence for you is that if something is, if we can burn something, that means it must have had energy.

37. Brianna: Yeah.

38. Mark: Because it's able to burn.

39. Christopher: It, it, I don't think it's energy, it's part of something that makes energy. It's not energy itself.

40. Brianna: But then if it doesn't have energy itself, then, you, we can't say that WE have energy because we don't have energy ourself, we just...

41. Christopher (smiling): I hate this.

42. Mark: Do you?

43. Brianna: Yes.

44. (Christopher nods.)

45. Danielle: We keep going from like one topic to the next and then another one and then like (compare to this one?) and then one, like (inaudible).

46. Brianna: No, well, well, you die. You start dying. But you can burn dead things, too.

47. (Christopher and Danielle are talking, but I cannot understand what they are saying.) 
48. Brianna: Well, I'm saying, you can! (Laughing) You can burn dead things, and they don't have energy and yet you seem to get these flames.

49. Christopher: Are you going against your own?

50. Brianna: Yes, I am! (?) So shush you! I'm working it through in my mind!

51. Mark: That's good. I like that.

52. Emily: Leaves are a source of energy, then.

53. Brianna: Yes.

54. Mark: So, I, I wanna come back to, aside from the issue of kind of living versus dead, (does that burn?), aside from that, I wanna go back to the motion issue. So how do we, how do we figure this out? I mean, so if the leaves don't move without the wind, does that mean the leaves don't have energy?

55. Brianna: No.

56. Mark: Why?

57. Brianna: Well, because, the bus, you know.

58. Mark: So the bus has energy because it was...

59. Brianna: Well, does it have energy, or does it just use energy? I mean, it's, it's a metal thing! It's a thing! Metal.

60. Christopher: The bus has the energy to use energy.

61. Emily: But doesn't everything like use energy?

62. Mark: (To Christopher) What do you mean by that?

63. Christopher: Because when you just, like, press the pedal, the whole bus just, like, takes the gas, turns it into, like.

64. Brianna: Well it USES that energy the gas has.

65. Christopher: So it uses YOUR energy to make the bus move.

66. Mark: So are you saying the, the, like the gasoline is the energy?

67. Brianna: Yeah, the gasoline is the energy, and the bus USES the energy to power itself. Like, you know, the leaves use the wind to MOVE. And like we use, you know, whatever we have insides our bodies to FUNCtion and all that good stuff.

68. Mark: So what if, um, so go to like the, like, the rolling ball. So you see a ball rolling, uh, on the ground. Does that, does that have energy?

69. Christopher: Energy can't (go?) on its own. Cause, like, you always, like, need a helper, and then, like, it goes.

70. Mark: So aside from, we know that, like, I gave it a push. But forget that. Like, (inaudible), we don't see anything pushing it. We just see it rolling. Or let's say, let's just say we set a ball on a hill. And it starts rolling down the hill. Does that ball have energy?

71. Brianna: Does the ball ITSELF have energy, or...?

72. (Christopher and Danielle groan.)

73. Danielle: I don't know, can you burn it? (Laughter)

74. Brianna: Yes!

75. Mark: I think, aside from that. I mean, I think we can say that about, about anything, right?

76. Brianna: Yeah.
77. Mark: Which is fine.

78. Brianna: I said my, I so just said the things that can (inaudible), the things that can use, it doesn't need energy to burn. I said dead things can burn. But, um, no, uh, I don't know, because I just want to say that, you know, it's...

79. Christopher: No, ball on its own doesn't have, you're giving it energy.

80. Brianna: ...I just wanna say cause it's rolling down the hill because of gravity.

81. Mark: (Responding to Christopher) What do you mean? I, but I'm just letting it roll downhill.

82. Brianna: Yeah, because of gravity.

83. Christopher: Yeah, but could I drop it?

84. Mark: Yeah, uh, a different scenario.

85. Brianna: You set it down.

86. Christopher: You set it down.

87. Brianna: And then I feel like gravity pulls it down.

88. Christopher: Yeah, so then there's like another force that helps it.

89. Brianna: But gravity is a type of energy.

90. Mark: So it's just, it's just forces, there's no energy involved?

91. Danielle: There's more than one source of energy helping it to move.

92. Christopher: Yeah, there's energy involved but it's not IN the ball.

93. Brianna: Isn't there, like, I know there's different types. There's like, you know, kinetic, um, molecular, and then some other stuff, motion. Well, I don't, I only remember those two!

94. (Christopher puts his head in his hands.)

95. Brianna: Energy in motion. (inaudible)

96. Mark: Why don't you guys try to work through those last three?

\section{APPENDIX C: FULL TRANSCRIPT FROM ALEX'S CLASS}

Throughout this transcript, parenthetical references indicate nonverbal utterances or ambiguities in our transcription.

1. Alex: Okay, stick with the old argument. (laughs) Uh, Jason, and then Nigel, and then Geoff.

2. Jason: I'm not sure if, if she loses energy or not, but if she doesn't, then we conclude that, um, that it would be, um, D, because if she doesn't lose energy-

3. Alex: Yeah.

4. Jason: She starts out with mgh-

5. Alex: Okay.

6. Jason: So, mass times gravity times height, um, I mean it will always be mgh, so, um, for potential, so if she starts out with mgh with the backpack, then, um, she still has, she's using the mgh energy-

7. Alex: Okay.

8. Jason: To swing up, she won't swing as far because the, um- 
9. Alex: Because m's bigger.

10. Jason: Yeah because m's bigger.

11. Alex: So $h$ has to be lower.

12. Jason: And then once $m$ goes back lower, the $h$ has to be bigger-

13. Alex: Okay.

14. Jason: So if you can prove that she doesn't lose energy, then it's D.

15. Alex: Okay, so if, if that quantity mgh, the total energy, if mgh, that product is always the same number, then Jason's got it figured out. So then for him the question is mgh always the same? He's just making himself a different question to think about, it's a good question to think about. Nigel?

16. Nigel: All right, my way of thinking about it is I went back to Granny and Ambrose.

17. Alex: Granny and Ambrose, yes, go back to Granny and Ambrose!

18. Nigel: All right, so we concluded that when she was rolling, right, and she picked him up-

19. Alex: Yeah.

20. Nigel: She lost speed.

21. Alex: She lost speed, absolutely.

22. Nigel: All right, so I'm thinking in my head, okay, so she would lose speed which means that her distance would not be as far as if she had just let him go.

23. Alex: Okay.

24. Nigel: All right? So I was picturing, let's say she's on a half-pipe.

25. Alex: All right, let's say she's on a half-pipe, sure.

26. Nigel: I'm trying to (inaudible)...

27. Alex: All right, Granny and Ambrose on the half-pipe!

28. Nigel: All right, so she's at the top, right?

29. Alex: Yep.

30. Nigel: She picks up Ambrose.

31. Alex: Yep. (acting this out)

32. Nigel: She's slowing down the whole way until she gets to a certain point-

33. Alex: Okay.

34. Nigel: Which is lower than where she started.

35. Alex: That's right.

36. 280. Nigel: Coming back down, she's going a lot faster because she has Ambrose, this kid in her hand, right?

37. Alex: Okay.

38. Roy: Why's she going faster?

39. Student: Yeah, that's what I'm-

40. Alex: Why's she going faster?

41. Student: Because of mass-

42. Nigel: Ahhh, ahhh, wait, wait-

43. Alex: All right, we'll let you criticize in a second, let's let Nigel finish.

44. Nigel: All right, so when she gets back down, she lets Ambrose go.

45. Alex: Lets Ambrose go, okay. (still acting this out)
46. Nigel: She's still moving, but she'll be moving - I lost it, damn I lost it!

47. Alex: When she lets Ambrose go, does she get a boost? Or does she just keep going at her same speed? Or something different? Does she slow down when she lets Ambrose go, does she continue at the same speed when she lets Ambrose go, or does she get a boost by letting Ambrose go?

48. Nigel: A tiny boost because now her mass is less and her velocity would be more because-

49. Alex: Okay, so you would be in the camp that seems to argue $\mathrm{H} 1$ is small but then $\mathrm{H} 1, \mathrm{H} 2$ goes back to being big.

50. Nigel: Yeah.

51. Alex: Okay. Roy?

52. Roy: Okay, um, I'm thinking my final question is now how can the backpack put a force, I think Larry made the best point earlier.

53. Alex: Okay.

54. Roy: How can the backpack put a force on her?

55. Alex: How can the backpack put a force on her?

56. Roy: Yeah, and you can drop the backpack, but how is it going to force you to go one way?

57. Alex: That's right.

58. Roy: So if you're going down in velocity-

59. Alex: Yeah.

60. Roy: With the backpack, the velocity slowed down, we all agree, because you picked up more mass.

61. Alex: Mm-hmm.

62. Roy: So now our velocity's smaller.

63. Alex: Yeah.

64. Roy: $1 / 2 \mathrm{k}$ or mv squared.

65. Alex: Yep.

66. Roy: Velocity's smaller, you get down to the bottom, you drop the mass, there's no way to really speed up unless the mass is putting a force on you, so you lose energy to that mass, whatever it is-

67. Alex: Mm-hmm.

68. Roy: And so now we don't have to solve for mgh again or $1 / 2 \mathrm{mv}$ squared because we don't have the same amount of kinetic energy, or the amount of energy that we started at the beginning with.

69. Alex: Okay, so this seems to be addressing Jason's question, and Jason said if he could show that the energy was always the same, then D would be the correct answer. And you seem to think that the energy is not the same.

70. Roy: Unless the backpack magically puts a force, I just don't know how it would.

71. Alex: Okay, so we can't think of how, Roy can't think of how the backpack would put a force on the girl, right, so, to get a boost. Larry?

72. Larry: I just have one question. Can we apply, um, circular motion to this because it's on a swing?

73. Alex: Okay, sure, the rules of circular motion apply. There's, there's certainly a force coming from the rope that's making her swing in a circle. I'm not sure how that 
influences your answer, but that's certainly true, it does have elements of circular motion involved. Jason?

74. Jason: All right, you said that if I can prove that we don't lose energy-

75. Alex: Yeah.

76. Jason: It would work, so, um, so wouldn't it be the same as all, like, let's say instead of her picking up the backpack, someone was standing next to her and they put the backpack on her lap. Right?

77. Alex: All right.

78. Jason: So if they, they, um, I don't that that's adding any energy if they didn't drop, they just place it onto her lap-

79. Alex: At the lowest point.

80. Jason: Yeah, not adding, so not adding-

81. Alex: Okay.

82. Jason: Any energy, just placing it there-

83. Alex: Okay.

84. Jason: And then also take the backpack and move it at the lowest point next time, so that should have the same result as her picking it up and dropping it, correct? I mean, if-

85. Alex: Right, so okay, you just presented a-

86. Jason: But if that's true, then-

87. Alex: Let's, okay, let's quiet down for a second, there's a few too many people talking at once. So Jason says, is thinking about an alternate way, thinking about someone standing there, and as she comes down the person hands the backpack to her, and on the way off she hands the backpack back to the person-

88. Nigel: That's different, that, no-

89. Alex: That's-

90. Nigel: That wouldn't be the same thing because-

91. Alex: That's, that strikes me as the same problem, now how does that, does that give you any more insight, thinking about it that way?

92. Jason: Um, because there have been people arguing that for some reason since the backpack falls or such, that would somehow mean that she lost energy-

93. Alex: Yeah.

94. Jason: So it should be the same thing, the same problem like you said, if someone just gave her the backpack, and the backpack's not falling in that situation, there's no, I don't see any reason that she would lose energy, she should have the same amount.

95. Alex: Okay, so in that case-

96. Jason: The backpack's falling because the gravity's pulling it, not because she gave it energy to make it fall.

97. Alex: Okay, so Geoff, was Geoff's point-

98. Student: (inaudible)...

99. Alex: All right, back to Geoff's point that the backpack falls, Jason has an issue with the backpack falling, was that your point, Geoff, that the backpack falls?

100. Geoff: No, my point was the backpack has the same speed, it does not, the backpack does not lose speed when she lets it go.
101. Alex: Okay, so Geoff's point I think wasn't that it fell, it has some velocity this way, and if there were, depending on how far away the ground were, the backpack's gonna fall in a parabola to the ground, but it's not so much the falling that Geoff is concerned with, it's that this velocity he's concerned with.

102. Jason: No but I mean, um, wouldn't it be, sorry, wouldn't it be the same thing? I mean, like, it wouldn't be the same thing if somebody hands her the backpack?

103. Geoff: Yeah, but when-

104. Jason: It'd be the same problem?

105. Geoff: But when she hands it back, though-

106. Alex: Yeah.

107. Geoff: Like, if you swing down and you like, like, just let go and it falls in their hands, you're gonna move back-

108. Jason: No but you place it onto her, you don't drop it onto her, or-

109. Geoff: But you can't stop it.

110. Alex: So it's like, it's like a handoff, you come down, you hold it like a football handoff, you just come down and someone's waiting to catch it, they just catch it, right?

111. Geoff: You would move back.

112. Student: Yeah.

113. Jason: Same thing when she picks it up because-

114. Alex: What do you think?

115. Geoff: So that's why she slows down-

116. Jason: Yeah, that's what I'm saying, the same thing.

117. Geoff: All right, so-

118. Jason: Yeah, both problems are the same, I thought, if you, like both problems are the same, if you hand it to her or if you pick it up, right? So, on the way back down, if she was picking it up and handing it off, are you saying that she would lose energy by letting go of it?

119. Geoff: No, I'm saying that she loses energy when she picks it up at the beginning, sorry, she loses speed when she picks it up at the beginning-

120. Jason: Yeah.

121. Geoff: She comes back down, she loses some momentum because she's not gaining any speed or mass by letting go of that backpack. Right?

122. Jason: Well, she starts out with-

123. Sara: Her mass is changing.

124. Jason: The thing is, does energy stay the same the whole time, or-

125. Geoff: No.

126. Jason: It doesn't? So she loses energy when she hands off the backpack?

127. Geoff: Yes.

128. Jason: Okay, so she hands off the backpack-

129. Nigel: Jason-

130. Jason: She has the same energy as before she dropped it? 
131. Nigel: Jason, can I (inaudible)...

132. Geoff: Yes.

133. Jason: Okay, (inaudible)... I'm not sure, I need to think about it.

134. Alex: What have, let's see, what if we imagine the backpack as, as an anvil, a really heavy anvil, okay, and the person that's handing off the anvil and picking it up is, is a three-year-old girl. Okay? She's able to hold up the anvil and present it, as Thalia swings down and scoops it up off her hands. Now Thalia's swinging back down with the anvil ready to hand it off to the girl. What's gonna happen?

135. Student: She's gonna get knocked back.

136. Alex: She's gonna get knocked back, why?

137. Student: Because it has velocity (inaudible)...

138. Student: It has a lot of kinetic energy.

139. Alex: Does that, does that help us think about where the momentum is going over the course of the problem, or does that not help at all?

140. Student: It's transferred to the backpack.
[1] NGSS Lead States, Next Generation Science Standards: For States, By States (National Acad. Press, Washington, DC, 2013).

[2] Common Core State Standards Initiative, Common Core State Standards for Mathematics (National Governors Association Center for Best Practices and the Council of Chief State School Officers, Washington, DC, 2010).

[3] A. D. Robertson, L. J. Atkins, J. Richards, and D. M. Levin, What is Responsive Teaching?, in Responsive Teaching in Science and Mathematics, edited by A. D. Robertson, R. E. Scherr, and D. Hammer, (Routledge, New York, NY, 2016), p. 1-35.

[4] D. Hammer, F. Goldberg, and S. Fargason, Responsive teaching and the beginnings of energy in a third grade classroom, Rev. Sci. Math. ICT Educ. 6, 51 (2012).

[5] E. Duckworth, "The Having of Wonderful Ideas" and other Essays on Teaching and Learning, 3rd ed. (Teachers College Press, New York, NY, 2006).

[6] D. Hammer, Student resources for learning introductory physics, Am. J. Phys. 68, S52 (2000).

[7] D. Hammer, The variability of student reasoning, lectures 1-3, in Proceedings of the Enrico Fermi Summer School, Course CLVI, edited by E. F. Redish and M. Vicentini (Italian Physical Society, Bologna, 2004), p. 279-340.

[8] D. Hammer and A. Elby, Epistemological resources, in Proceedings of the Fourth International Conference of the Learning Sciences, edited by $\mathrm{B}$. Fishman and $\mathrm{S}$. O'Connor-Divelbiss (Erlbaum: Mahwah, NJ, 2000), p. 4-5.

[9] D. Hammer, A. Elby, R. E. Scherr, and E. F. Redish, Resources, framing, and transfer, in Transfer of Learning from a Modern Multidisciplinary Perspective, edited by J. P. Mestre (Information Age, Charlotte, NC, 2005), p. 89-119.

[10] M. G. Sherin, V. R. Jacobs, and R. A. Philipp, Mathematics teacher noticing: Seeing through teachers' eyes, in Studies in Mathematical Thinking and Learning, edited by A. H. Schoenfeld (Routledge, New York, NY, 2011).

[11] T. P. Carpenter, E. Fennema, M. L. Franke, L. Levi, and S. B. Empson, Cognitively Guided Instruction: A Research-Based Teacher Professional Development Program for Elementary School Mathematics (NCISLA, Wisconsin Center for Education Research, University of Wisconsin, Madison, WI, 2000).
[12] D. M. Levin, Ph.D. thesis, University of Maryland, 2008.

[13] D. M. Levin, D. Hammer, and J. E. Coffey, Novice teachers' attention to student thinking, J. Teach. Educ. 60, 142 (2009).

[14] M. Lau, Ph.D. thesis, University of Maryland, 2010.

[15] J. L. Pierson, Ph.D. dissertation, University of Texas at Austin, Austin, 2008), p. 161.

[16] A. Colestock and T. Linnenbringer, Selective Archiving as a Tool for Supporting Mathematics Teacher Inquiry and Exploring Teachers' Sensemaking of Students' Mathematical Thinking, in Proceedings of the Annual Meeting of the American Educational Research Association (AERA, Denver, CO, 2010).

[17] M. G. Sherin and E. A. van Es, Effects of video club participation on teachers' professional vision, J. Teach. Educ. 60, 20 (2009).

[18] M. G. Sherin and E. A. van Es, Using video to support teachers' ability to notice classroom interactions, J. Tech. Teach. Educ. 13, 475 (2005).

[19] E. A. van Es and M. G. Sherin, Mathematics teachers' "learning to notice" in the context of a video club, Teach. Teach. Educ. 24, 244 (2008).

[20] E. A. van Es and M. G. Sherin, The influence of video clubs on teachers' thinking and practice, J. Math. Teach. Educ. 13, 155 (2010).

[21] V. R. Jacobs, L. L. C. Lamb, and R. A. Philipp, Professional noticing of children's mathematical thinking, J. Res. Math. Educ. 41, 169 (2010).

[22] K. Brodie, Working with learners' mathematical thinking: Towards a language of description for changing pedagogy, Teach. Teach. Educ. 27, 174 (2011).

[23] K. Gallas, Talking Their Way Into Science: Hearing Children's Questions and Theories, Responding with Curricula (Teachers College Press New York, NY, 1995).

[24] D. Schifter, Examining the Behavior of Operations: Noticing Early Algebraic Ideas, in Mathematics Teacher Noticing: Seeing through Teachers' Eyes, edited by M. G. Sherin, V. R. Jacobs, and R. A. Philipp (Routledge, New York, NY, 2011), p. 204-220.

[25] T. Wallach and R. Even, Hearing students: The complexity of understanding what they are saying, showing, and doing, J. Math. Teach. Educ. 8, 393 (2005). 
[26] D. Hammer, Discovery learning and discovery teaching, Cognit. Instr. 15, 485 (1997).

[27] D. L. Ball, With an eye on the mathematical horizon: Dilemmas of teaching elementary school mathematics, Elem. School J. 93, 373 (1993).

[28] J. E. Coffey, D. Hammer, D. M. Levin, and T. Grant The missing disciplinary substance of formative assessment, J. Res. Sci. Teach. 48, 1109 (2011).

[29] D. Levin, D. Hammer, A. Elby, and J. Coffey, Becoming a Responsive Science Teacher: Focusing on Student Thinking in Secondary Science (National Science Teachers Association Press, Arlington, VA, 2012).

[30] D. Hammer and E. van Zee, Seeing the Science in Children's Thinking: Case Studies of Student Inquiry in Physical Science (Heinemann Portsmouth, NH, 2006).

[31] V. R. Jacobs, M. L. Franke, T. P. Carpenter, L. Levi, and D. Battey, Professional development focused on children's algebraic reasoning in elementary school, J. Res. Math. Educ. 38, 258 (2007).

[32] L. T. Goldsmith and N. Seago, Using classroom artifacts to focus teachers' noticing: Affordances and opportunities, in Mathematics Teacher Noticing: Seeing Through Teachers' Eyes, edited by M. G. Sherin, V. R. Jacobs, and R. A. Philipp (Routledge, New York, NY, 2011), p. $169-187$.

[33] R. S. Russ, J. E. Coffey, D. Hammer, and P. Hutchison, Making classroom assessment more accountable to scientific reasoning: A case for attending to mechanistic thinking, Sci. Educ. 93, 875 (2009).

[34] P. Hutchison and D. Hammer, Attending to student epistemological framing in a science classroom, Sci. Educ. 94, 506 (2010).

[35] D. Chazan and D. L. Ball, Beyond being told not to tell, For the Learning of Math. 19, 2 (1999).

[36] B. W. Harrer, V. J. Flood, and M. C. Wittmann, Productive resources in students' ideas about energy: An alternative analysis of Watts' original interview transcripts, Phys. Rev. ST Phys. Educ. Res. 9, 023101 (2013).

[37] E. Fennema, M. L. Franke, T. P. Carpenter, and D. A. Carey, Using children's mathematical knowledge in instruction, Am. Educ. Res. J. 30, 555 (1993).

[38] T. P. Carpenter, E. Fennema, P. L. Peterson, C.-P. Chiang, and M. Loef, Using knowledge of children's mathematics thinking in classroom teaching: An experimental study, Am. Educ. Res. J. 26, 499 (1989).

[39] E. Fennema, T. P. Carpenter, M. L. Franke, L. Levi, V. R. Jacobs, and S. B. Empson, A longitudinal study of learning to use children's thinking in mathematics instruction, J. Res. Math. Educ. 27, 403 (1996).

[40] J. E. Lineback, The redirection: An indicator of how teachers respond to student thinking, J. Learning Sci. 24, 419 (2015).

[41] V. R. Jacobs, L. L. Lamb, R. A. Philipp, and B. P. Schappelle, Deciding how to respond on the basis of children's understandings, in Mathematics Teacher Noticing: Seeing Through Teachers' Eyes, edited by M. G. Sherin, V. R. Jacobs, and R. A. Philipp (Routledge, New York, NY, 2011), p. 97-116.

[42] A. C. Maskiewicz and V. A. Winters, Understanding the co-construction of inquiry practices: A case study of a responsive teaching environment, J. Res. Sci. Teach. 49, 429 (2012).

[43] S. B. Empson and V. R. Jacobs, Learning to listen to children's mathematics, in Tools and Processes in Mathematics Teacher Education, edited by D. Tirosh and T. Wood (Sense Publishers, The Netherlands, 2008) p. 257-281.

[44] National Research Council, A Framework for $K-12$ Science Education: Practices, Crosscutting Concepts, and Core Ideas, edited by H. Quinn, H. Schweingruber, and T. Keller (National Academies Press, Washington, DC, 2012).

[45] J. Richards, Ph.D. dissertation, University of Maryland, College Park, 2013.

[46] N. B. Kersting, K. B. Givvin, F. L. Sotelo, and J. W. Stigler, Teachers' analyses of classroom video predict student learning of mathematics: Further explorations of a novel measure of teacher knowledge, J. Teach. Educ. 61, 172 (2010).

[47] J. Hiebert and D. Wearne, Instructional tasks, classroom discourse, and students' learning in second-grade arithmetic, Am. Educ. Res. J. 30, 393 (1993).

[48] G. B. Saxe, M. Gearhart, and M. Seltzer, Relations between classroom practices and student learning in the domain of fractions, Cognit. Instr. 17, 1 (1999).

[49] J. Radoff et al., Responsive teaching in the age of highstakes testing: Does pursuing students' ideas mean they will perform poorly?, Sci. Children (to be published).

[50] B. Warren, C. Ballenger, M. Ogonowski, A. S. Rosebery, and J. Hudicourt-Barnes, Rethinking diversity in learning science: The logic of everyday sense-making, J. Res. Sci. Teach. 38, 529 (2001).

[51] S. B. Empson, Low-performing students and teaching fractions for understanding: An interactional analysis, J. Res. Math. Educ. 34, 305 (2003).

[52] J. Hudicourt-Barnes, The use of argumentation in Haitian Creole science classrooms, Harv. Educ. Rev. 73, 73 (2003).

[53] S. Michaels, Can the intellectual affordances of workingclass storytelling be leveraged in school?, Hum. Dev. 48, 136 (2005).

[54] A. S. Rosebery, M. Ogonowski, M. DiSchino, and B. Warren "The coat traps all your body heat": Heterogeneity as fundamental to learning, J. Learn. Sci. 19, 322 (2010)

[55] B. Warren, M. Ogonowski, and S. Pothier, "Everyday" and "Scientific": Rethinking dichotomies in modes of thinking in science learning, in Everyday Matters in Science and Mathematics, edited by R. Nemirovsky et al. (Lawrence Erlbaum Associates, Mahwah, NJ, 2005).

[56] A. S. Rosebery, B. Warren, and E. Tucker-Raymond, Developing Interpretive Power in Science Teaching, J. Res. Sci. Teach., J. Res. Sci. Teach. 53, 1571 (2015).

[57] P. Freire, Pedagogy of the Oppressed (Bloomsbury, New York, NY, 2000).

[58] D. M. Levin, A. S. Tudela, and M. Lau, Responsive Teaching and Power: Toward Practice of Anti-Oppressive Science Pedagogy (American Association of Physics Teachers, Sacramento, CA, 2016).

[59] A. C. Maskiewicz, Navigating the challenges of teaching responsively: An insider's perspective, in Responsive 
Teaching in Science and Mathematics, edited by A. D. Robertson, R. E. Scherr, and D. Hammer (Routledge, New York, NY, 2016), p. 105-125.

[60] L. Jaber, Ph.D. dissertation, Tufts University, Medford, 2014.

[61] J. Radoff and D. Hammer, Attention to student framing in responsive teaching, in Responsive Teaching in Science, edited by A. D. Robertson, R. E. Scherr, and D. Hammer, (Routledge, New York, NY, 2016), p. 189-202.

[62] T.-R. Sikorski, Understanding responsive teaching and curriculum from the students' perspective, in Responsive Teaching in Science, edited by A. D. Robertson, R. E. Scherr, and D. Hammer (Routledge, New York, NY, 2016), p. 85-104.

[63] R. Dorph and B. Chi, Productive Beginnings: The Final Evaluation Report for the Learning Progressions in Scientific Inquiry and Energy Project (NSF \#0732233) (University of California, Berkeley, CA, 2013), p. 37.

[64] M. G. Sherin and S. Y. Han, Teacher learning in the context of a video club, Teach. Teach. Educ. 20, 163 (2004).

[65] E. van Es, A Framework for learning to notice student thinking, in Mathematics Teacher Noticing: Seeing Through Teachers' Eyes, edited by M. G. Sherin, V. R. Jacobs, and R. A. Philipp (Routledge, New York, NY, 2011), pp. 134-151.

[66] D. L. Ball and F. M. Forzani, The work of teaching and the challenge for teacher education, J. Teach. Educ. 60, 497 (2009).

[67] M. Lampert et al., Using designed instructional activities to enable novices to manage ambitious mathematics teaching, in Instructional Explanations in the Disciplines, edited by M. K. Stein and L. Kucan (Springer Science +Business Media, New York, NY, 2010), pp. 129-141.

[68] M. Lampert, M. L. Franke, E. Kazemi, H. Ghousseini, A. C. Turrou, H. Beasley, A. Cunard, and K. Crowe, Keeping It Complex: Using Rehearsals to Support Novice Teacher Learning of Ambitious Teaching, J. Teach. Educ. 64, 226 (2013).

[69] M. Windschitl, J. Thompson, M. Braaten, and D. Stroupe, Proposing a core set of instructional practices and tools for teachers of science, Sci. Educ. 96, 878 (2012).

[70] P. Grossman, K. Hammerness, and M. McDonald, Redefining teaching, re-imagining teacher education, Teachers and Teaching: Theory Pract. 15, 273 (2009).

[71] M. McDonald, E. Kazemi, and S. S. Kavanagh, Core practices and pedagogies of teacher education: A call for a common language and collective activity, J. Teach. Educ. 64, 378 (2013).

[72] H. Ghousseini, H. Beasley, and S. Lord, Investigating the potential of guided practice with an enactment tool for supporting adaptive performance, J. Learn. Sci. 24, 461 (2015).

[73] E. Furtak, Toward learning progressions as teacher development tools, in Paper presented at the Learning Progressions in Science (LeaPS) Conference, Iowa City, IA (2009), http://www.education.msu.edu/projects/leaps/ proceedings/Default.html.

[74] E. M. Furtak, K. Kiemer, R. K. Circi, R. Swanson, V. de León, D. Morrison, and S. C. Heredia, Teachers'
Formative Assessment Abilities and Their Relationship to Student Learning: Findings from a Four-Year Intervention Study, Instr. Sci. 44, 267 (2016).

[75] T. P. Carpenter, E. Fennema, and M. L. Franke, Cognitively guided instruction: A knowledge base for reform in primary mathematics instruction, Elem. School J. 97, 3 (1996).

[76] E. Fennema, T. P. Carpenter, M. L. Franke, and D. A. Carey, Learning to use children's mathematical thinking: A case study, in Schools, Mathematics, and the World of Reality, edited R. B. Davis and C. A. Maher, (Allyn and Bacon, Needham Heights, MA, 1993), pp. 93-117.

[77] M. L. Franke and E. Kazemi, Learning to teach mathematics: Focus on student thinking, Theory Into Practice 40, 102 (2001).

[78] S. Grossman and J. Williston, Teaching strategies: strategies for helping early childhood students learn appropriate teaching practices, Childhood Education 79, 103 (2002).

[79] R. S. Russ, R. E. Scherr, D. Hammer, and J. Mikeska, Recognizing mechanistic reasoning in student scientific inquiry: A framework for discourse analysis developed from philosophy of science, Sci. Educ. 92, 499 (2008).

[80] L. J. Atkins and B. W. Frank, Examining the products of responsive inquiry, in Responsive Teaching in Science and Mathematics, edited A. D. Robertson, R. E. Scherr, and D. Hammer, (Routledge, New York, NY, 2016), pp. $56-84$.

[81] R. A. Engle and F. R. Conant, Guiding principles for fostering productive disciplinary engagement: Explaining an emergent argument in a community of learners classroom, Cognit. Instr. 20, 399 (2002).

[82] R. Bresser and S. Fargason, Becoming Scientists: InquiryBased Teaching in Diverse Classrooms, Grades 3-5 (Stenhouse, Portland, ME, 2013).

[83] D. E. Meltzer and V. K. Otero, Transforming the preparation of physics teachers, Am. J. Phys. 82, 633 (2014).

[84] V. Otero, S. Pollock, and N. Finkelstein, A physics department's role in preparing physics teachers: The Colorado learning assistant model, Am. J. Phys. 78, 1218 (2010).

[85] M. E. Loverude, B. L. Gonzalez, and R. Nanes, Inquirybased course in physics and chemistry for preservice K-8 teachers, Phys. Rev. ST Phys. Educ. Res. 7, 010106 (2011).

[86] Z. Hrepic, P. Adams, J. Zeller, N. Talbott, G. Taggart, and L. Young, Developing an inquiry-based physical science course for preservice elementary teachers, in Proceedings of the 2005 Physics Education Research Conference, edited by P. Heron, L. McCullough, and J. Marx (AIP Press: Melville, NY, 2006), pp. 121-124.

[87] Task Force on Teacher Education in Physics (T-TEP), Transforming the Preparation of Physics Teachers: A Call to Action, edited by D. E. Meltzer, M. Plisch, and S. Vokos (American Physical Society, College Park, MD, 2012).

[88] L. C. McDermott, P. S. Shaffer, and C. P. Constantinou, Preparing teachers to teach physics and physical science by inquiry, Phys. Educ. 35, 411 (2000). 
[89] N. Finkelstein, C. Turpen, S. Pollock, M. Dubson, S. Iona, C. Keller, and V. Otero, Evaluating a model of research-based practices for teacher preparation in a physics department: Colorado PhysTEC, 2005 Physics Education Research Conference(AIP Press Melville, NY, 2006).

[90] National Council of Teachers of Mathematics, Principles and standards for school mathematics. (Reston, VA, 2000).

[91] F. Erickson, Qualitative methods in research on teaching, in Handbook of Research on Teaching, edited by M. C. Wittrock (Macmillan, New York, 1986), pp. 119-161.

[92] E. G. Guba and Y. S. Lincoln, Paradigmatic controversies, contradictions, and emerging confluences, in The Sage Handbook of Qualitative Research, edited by N.K. Denzin and Y. S. Lincoln (Sage Publications, Inc., Thousand Oaks, CA, 2005), pp. 191-215.

[93] J. W. Creswell, Research Design: Qualitative, Quantitative, and Mixed Methods Approaches, 3rd ed. (Sage Publications, Inc., Thousand Oaks, CA, 2009).

[94] J. W. Willis, World views, paradigms, and the practice of social science research, in Foundations of Qualitative Research: Interpretive and Critical Approaches (Sage Publications, Inc., Thousand Oaks, CA, 2007).

[95] W. A. Firestone, Meaning in method: The rhetoric of quantitative and qualitative research, Educ. Res. 16, 16 (1987).

[96] E. Bredo, Philosophies of educational research, in Handbook of Complementary Methods in Education Research, edited by J. L. Green et al. (Lawrence Erlbaum Associates, Mahwah, NJ, 2006). pp. 3-31.

[97] F. Erickson, Some Thoughts on "Proximal" Formative Assessment of Student Learning. Yearbook of the Natl. Soc. Study of Educ. 106, 186 (2007).

[98] E. G. Mishler, Meaning in context: Is there any other kind?, Harv. Educ. Rev. 49, 1 (1979).

[99] P. A. Moss, D. C. Phillips, F. D. Erickson, R. E. Floden, P. A. Lather, and B. L. Schneider, Learning from our differences: A dialogue across perspectives on quality in education research, Educ. Res. 38, 501 (2009).

[100] R. E. Scherr, H. G. Close, E. W. Close, V. J. Flood, S. B. McKagan, A. D. Robertson, L. Seeley, M. C. Wittmann, and S. Vokos, Negotiating energy dynamics through embodied action in a materially structured environment, Phys. Rev. ST Phys. Educ. Res. 9, 020105 (2013).

[101] R. E. Scherr, H. G. Close, S. B. McKagan, and S. Vokos, Representing energy. I. Representing a substance ontology for energy, Phys. Rev. ST Phys. Educ. Res. 8, 020114 (2012).

[102] R. E. Scherr, H. G. Close, E. W. Close, and S. Vokos, Representing energy. II. Energy tracking representations, Phys. Rev. ST Phys. Educ. Res. 8, 020115 (2012).

[103] R. E. Scherr and A. D. Robertson, The productivity of "collisions generate heat" for reconciling an energy model with mechanistic reasoning: A case study, Phys. Rev. ST Phys. Educ. Res. 11, 010111 (2015).

[104] R. E. Scherr, A. D. Robertson, L. Seeley, and S. Vokos, Content knowledge for teaching energy: An example from middle-school science. in 2013 Physics Education Research Conference (AIP Press, Melville, NY, 2013).

[105] P. Hewitt, Thalia on a Swing, Phys. Teach. 47, 332 (2009).

[106] B. Jordan and A. Henderson, Interaction analysis: Foundations and practice, J. Learn. Sci. 4, 39 (1995).

[107] J. A. Maxwell, Understanding and validity in qualitative research, Harv. Educ. Rev. 62, 279 (1992).

[108] Available from: http://cipstrends.sdsu.edu/ responsiveteaching/carmodule/activities/act35/examples/ sharon_y1.html.

[109] M. C. O'Connor and S. Michaels, Aligning academic task and participation status through revoicing: Analysis of a classroom discourse strategy, Anthropology Educ. Quart. 24, 318 (1993).

[110] L. Jaber, Attending to students' epistemic affect, in Responsive Teaching in Science and Mathematics, edited by A. D. Robertson, R. E. Scherr, and D. Hammer (Routledge, New York, NY, 2016), pp. 162-188.

[111] L. Jaber and D. Hammer, Learning to feel like a scientist, Sci. Educ. 100, 189 (2016).

[112] L. C. McDermott, Preparing K-12 teachers in physics: Insights from history, experience, and research, Am. J. Phys. 74, 758 (2006).

[113] L. S. Shulman, Those who understand: Knowledge growth in teaching, Educ. Res. 15, 4 (1986).

[114] L. S. Shulman, Knowledge and teaching: Foundations of the new reform, Harv. Educ. Rev. 57, 1 (1987).

[115] D. L. Ball, M. H. Thames, and G. Phelps, Content knowledge for teaching: What makes it special?, J. Teach. Educ. 59, 389 (2008).

[116] D. L. Ball and H. Bass, Toward a practice-based theory of mathematical knowledge for teaching, in Proceedings of the 2002 Annual Meeting of the Canadian Mathematics Education Study Group, edited by B. Davis and E. Simmt (CMESG/GCEDM, Edmonton, AB, 2003), p. 3-14. 